\title{
Molecular phylogenetics and comparative anatomy of Kimberleytrachia Köhler, 2011 - a genus of land snail endemic to the coastal Kimberley, Western Australia with description of new taxa (Gastropoda, Camaenidae)
}

\author{
Francesco Criscione ${ }^{1}$, Frank Köhler ${ }^{1,2}$ \\ ${ }^{1}$ Australian Museum, 6 College Street, Sydney NSW 2010, Australia \\ ${ }^{2}$ E-mail:frank.koehler@austmus.gov.au
}

Key words: genetic distances, Helicoidea, mitochondrial DNA, new species, Stylommatophora

\begin{abstract}
Kimberleytrachia Köhler, 2011 is a genus of camaenid land snail endemic to the Western Australian Kimberley region. It comprises twelve previously recognised species, all of which occur within the high precipitation zone along the north-western coast between the Admiralty Gulf and King Sound and within less than about $50 \mathrm{~km}$ distance from the coast. By evaluating the variation in shell and genital anatomy as well as the differentiation in the mitochondrial markers $16 \mathrm{~S}$ and COI, we assess the monophyly of Kimberleytrachia with respect to other camaenid genera from north-western Australia. In addition, we newly describe six species (K. jacksonensis n. sp., K. leopardus n. sp., $K$. nelsonensis n. sp., K. serrata n. sp., K. setosa n. sp. and $K$. silvaepluvialis $\mathrm{n}$. sp.) based on comparative morphology and mitochondrial DNA differentiation. We found that a rather smooth, weakly elevated shell and, in particular, the complex penial anatomy are key morphological characteristics of Kimberleytrachia. Its constituent species are differentiated by a combination of shell and genital features and their morphological disparity appears to be more pronounced when species occur in sympatry. While island species are usually narrowly endemic to one or a few islands, the mainland species have much larger distributional ranges. One new species from the Maret and Berthier Islands, Bonaparte Archipelago, is phylogenetically and morphologically so distinct from Kimberleytrachia that it is recognized as a new monotypic genus, Succochlea $\mathrm{n}$. gen.
\end{abstract}

\section{Contents}

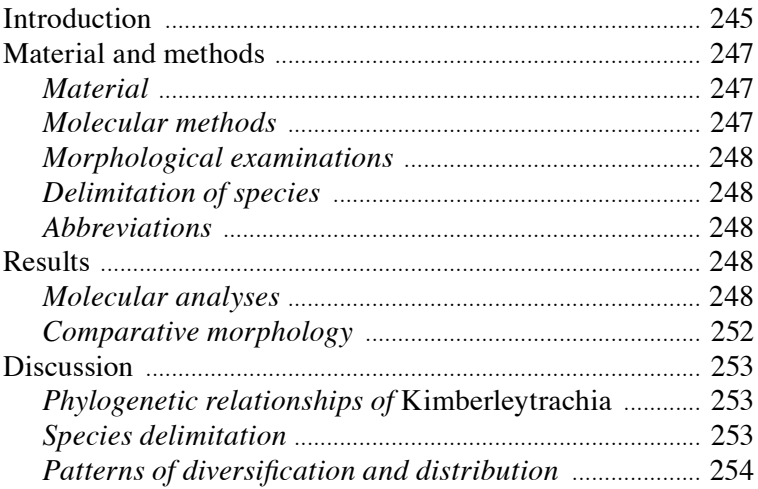

Acknowledgements ………………………………………....... 256

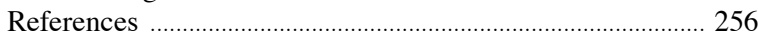

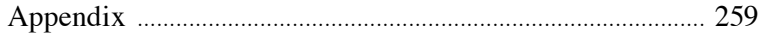

\section{Introduction}

The Kimberley Region, a comparatively pristine region in Western Australia has yet widely escaped the impacts of urban, industrial and agricultural development due to its remoteness and rugged terrain. As a result, the Kimberley is an area of high significance for natural heritage conservation across terrestrial and marine environments. The inaccessibility of vast parts of the Kimberley has also hampered the scientific exploration of its biodiversity, rendering current knowledge of the Kimberley's fauna and flora patchy. However, several large surveys conducted during the past four decades have improved the documentation of biotic patterns throughout the Kimberley highlighting this region as one of Australia' s biodiversity hotspots (McKenzie, 1991; Gibson and McKenzie, 2012).

Thanks to the hallmark works of Alan Solem, the Kimberley is known to support an exceptionally diverse fauna of camaenid land snails. Solem $(1979,1981 \mathrm{a}, \mathrm{b}$, $1984,1985,1988,1997)$ revised the entire camaenid fauna known at the time and described many new taxa, bringing the count of described species from about 30 to 120 . However, this number was still based on rather patchy collections undertaken mostly at readily accessible locations along major roads and the coast. Thus, there had been little doubt that future surveys in yet un-sampled areas would unearth many additional species. Our on-going revisionary work, which has mostly been based on newly collected materials from more remote locations, has since doubled the number of known camaenid species from the Kimberley to about 260 (e.g. Köhler, 2010a, b, 2011a, b, c; Criscione et al., 
2012; Köhler and Johnson, 2012; Köhler and Shea, 2012; Köhler and Criscione, 2013; Criscione and Köhler, 2013a, b, c, 2014a, b).

The patterns of distribution and diversity of land snail communities throughout the Kimberley are governed by rainfall, topography, soil and vegetation types (Solem and McKenzie, 1991; Gibson and Köhler, 2012; Köhler et al., 2012), and predominantly characterised by narrow range endemism and allopatry. Previous studies of camaenids from the Kimberley mainland and from offshore islands have shown that on average species ranges are restricted to a diameter of about $20 \mathrm{~km}$ or even less (Solem, 1991; Cameron, 1992; Köhler, 2011b). The same works have revealed a correlation between preferred habitat and the extent of species distributions. Along the coasts, many camaenids occur in rainforest habitats (i.e., vine thickets) but not in the surrounding, more open wood- and bushland. Because rainforest vegetation is restricted to small protected pockets, such rainforest species are often narrowly endemic to one or few rainforest patches (Solem, 1991; Köhler, 2010b, $2011 b$, c). Further inland, however, where rainforest patches are sparse or entirely lacking, camaenid snails inhabit more open woodland and rocky habitats. Since these habitats are more widespread and less fragmented, inland species tend to have much wider ranges. However, the species richness of more xeric regions is much lower than this of the sub-humid parts of the Kimberley. The richest land snail communities are found in vine thicket patches in the high precipitation zone of the north-western coastal region between the Admiralty Gulf to the north and the Camden Sound to the south (Solem and McKenzie, 1991). Altogether fifteen camaenid genera are represented in this region, some of which have recently been revised based on comparative analyses of morphological and mitochondrial DNA differentiation, such as Baudinella Thiele, 1931 and Retroterra Solem, 1985 (Criscione and Köhler, 2014a) as well as Setobaudina Iredale, 1933 (Criscione and Köhler, 2013b).

The present study is dedicated to yet another genus occurring in the high precipitation zone, Kimberleytrachia Köhler, 2011. This genus comprises twelve presently recognised species. Almost all species occupy vine thickets between the Montague Sound and Collier Bay and within less than $50 \mathrm{~km}$ distance from the coast (Fig. 1).

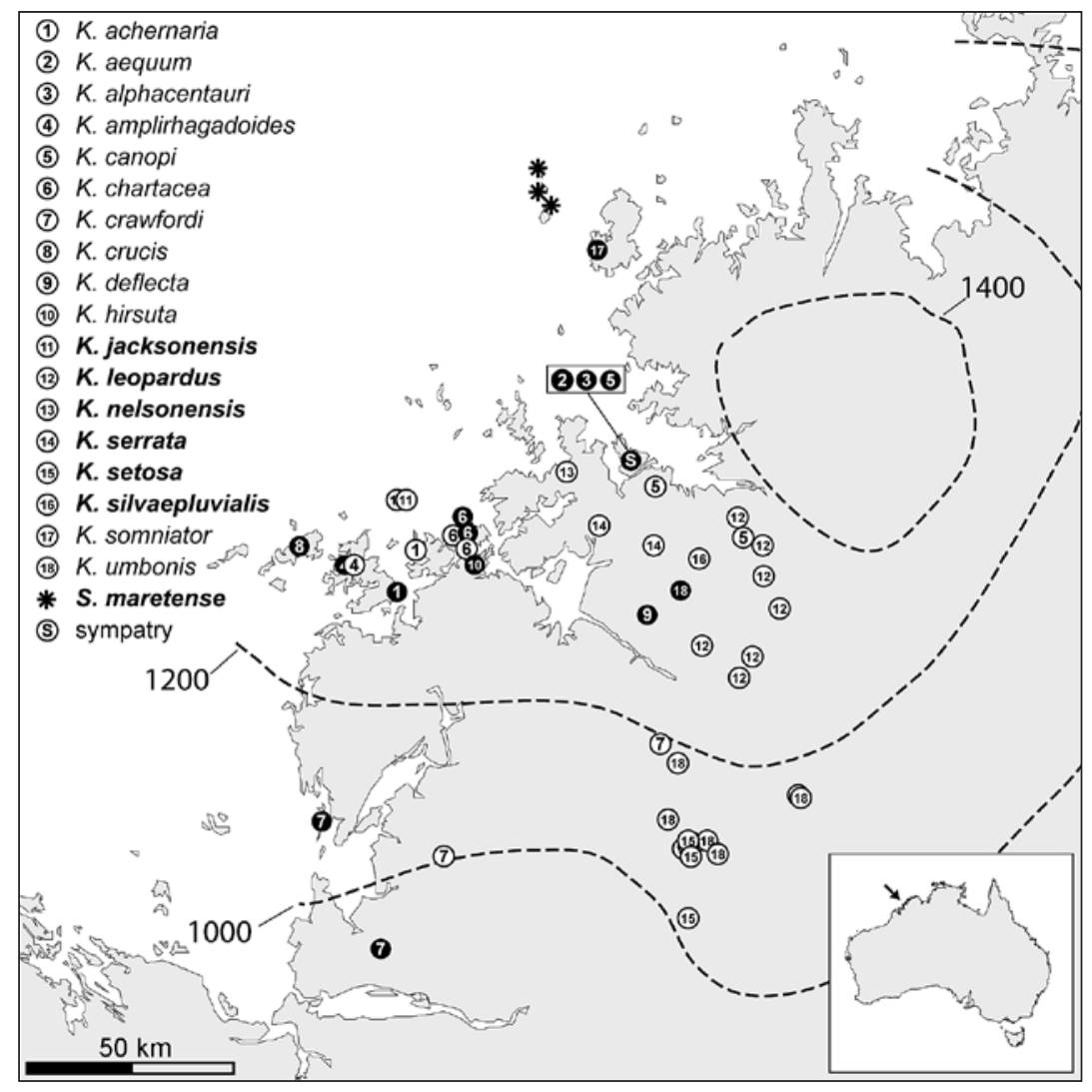

Fig. 1. Distribution of Kimberleytrachia species in the Kimberley, Western Australia. White dots $=$ new records, black dots $=$ records from Solem $(1979,1985)$ and Köhler (2011). Scale bar $=50 \mathrm{~km}$. Dashed lines indicate isohyets of average annual rainfall (in $\mathrm{mm}$ ). 
Available data indicate that Kimberleytrachia species are patchily distributed and narrowly endemic (Köhler, 2011b). As in most camaenids from the Kimberley, congeneric species are predominantly allopatric. Exceptionally three species occur in sympatry on Boongaree Island and two on Augustus Island (Köhler, 2011b).

Species now placed within Kimberleytrachia were originally affiliated with Torresitrachia Iredale, 1939 (Solem, 1979, 1985), another genus with superficially similar species having a moderately large and weakly elevated shell with wide aperture, an expanded and somewhat reflected lip and a saucer-shaped umbilicus. However, Kimberleytrachia and Torresitrachia can clearly be differentiated by features of their genitalia as well as their microscopic shell sculpture. In particular, the inner penial wall of Kimberleytrachia species does not exhibit the combination of distal pustules and proximal pilasters typical of Torresitrachia. Instead, it exhibits a combination of transverse or oblique lamellae and pilasters. Furthermore, the two genera pursue different aestivation strategies: Torresitrachia species are so-called 'free sealers' while Kimberleytrachia species seal themselves to hard substrates while aestivating ('rock sealers') (Köhler, 2011b).

Based on comparative analyses of molecular and morphological data, the present study aims to resolve the phylogenetic relationships of Kimberleytrachia with respect to other north-western Australian camaenids and to test its monophyly in particular with respect to Torresitrachia in order to revise the genus-level taxonomy. We also continue the taxonomic work of Solem (1985) and Köhler (2011b) at the species level by examining previously unstudied museum material and newly collected samples. Using a combination of anatomical and genetic features, we aim to correctly delimit species and to identify and formally describe new species.

\section{Material and methods}

\section{Material}

This study is based on ethanol preserved samples and dry shells deposited in the malacological collections of the Western Australian Museum, Perth (WAM) and the Field Museum of Natural History, Chicago (Table S1). Collection sites spanned an area of about $10,000 \mathrm{~km}^{2}$ in the central north-western Kimberley in Western Australia (Fig. 1). Samples from the same collection site are referred to as lots. Holotypes of newly described species are those dissected specimens, which were used to produce the anatomical illustrations figured herein.

\section{Molecular methods}

DNA was extracted from small pieces of foot muscle from up to four specimens per lot by use of a QIAGEN DNA extraction kit for animal tissue following the standard procedure of the manual. Fragments of the mitochondrial 16S rRNA (16S) and cytochrome c oxidase subunit 1 (COI) genes were amplified by PCR using the primer pairs 16Scs1 (Chiba, 1999) and 16Sbd1 (Sutcharit et al., 2007) and L1490 and H2198 (Folmer et al., 1994), respectively. Reactions were performed with annealing temperatures / elongation times of $55^{\circ} \mathrm{C}$ $/ 90 \mathrm{~s}$ for $16 \mathrm{~S}$ and $50^{\circ} \mathrm{C} / 60 \mathrm{~s}$ for COI, respectively. Both strands of PCR fragments were purified and cycle sequenced by use of the PCR primers. Electropherograms were corrected for misreads and forward and reverse strands were merged into one sequence file using CodonCode Aligner v. 3.6.1 (CodonCode Corporation, Dedham, MA). All sequences have been deposited in GenBank (Table S1). Sequence alignments were generated using MUSCLE as implemented in MEGA5 (Tamura et al., 2011). Sequence saturation was assessed for each mtDNA fragment by comparing values of the entropy-based index of substitution saturation (Iss) with its critical value (Iss.c). The test is implemented in DAMBE (Xia et al., 2003). Uncorrected pair-wise genetic distances were calculated using MEGA5 under the option 'pair-wise deletion of gaps'. For phylogenetic analyses, $16 \mathrm{~S}$ and $\mathrm{COI}$ sequence datasets were examined separately and concatenated into one partitioned dataset. Prior to the model-based phylogenetic analyses, the best-fit model of nucleotide substitution was identified for each gene partition separately by means of the Bayesian Information Criterion calculated with MrModeltest (Nylander, 2002). Partitioned models were applied in the Bayesian Inference (BI) analyses with parameters estimated from the data set. A Maximum Likelihood (ML) analysis was performed using RaxMLGui by applying the GTRGAMMA model (Silvestro and Michalak, 2010). One-hundred thorough ML bootstrap replicates, each with 10 runs, were performed to assess the branch support of the ML tree. Bayesian posterior probabilities of phylogenetic trees were estimated by running a 10,000,000 generations Metropolis-coupled Markov chain Monte Carlo (2 runs each with 4 chains, one of which was heated) as implemented by MrBayes vs. 3.2.1 (Ronquist and Huelsenbeck, 2003). A data partition was applied that allowed 
parameters to be estimated separately for each gene fragment and for each codon position of the COI gene. Sampling rate of the trees was 1,000 generations. Generations sampled before the chain reached stationary were discarded as burn-in. Stationarity was reached when the average standard deviation of split frequencies shown in MrBayes was less than 0.01 and the log likelihood of sampled trees reached a stationary distribution (Ronquist and Huelsenbeck, 2003).

\section{Morphological examinations}

Morphological characters of adult shells (dimension, colouration and sculpture) were assessed from all specimens. Adults were recognized by their fully developed apertural lip (Solem, 1985: 715). Shells were measured with callipers precise to $0.1 \mathrm{~mm}$. Characters measured were height $(\mathrm{H}=$ maximum dimension parallel to axis of coiling, including lip) and diameter (D = maximum dimension perpendicular to $\mathrm{H}$, including lip). The number of whorls (W), including protoconch, was counted precise to 0.1 as shown in Köhler (2011b: fig. 2). Representatives of each mtDNA clade were dissected in order to study the genital anatomy by use of a Leica M8 stereo microscope with drawing mirror. Genital anatomy was studied in two (in small lots) to five specimens per lot in order to confirm that morphological features were consistent in specimens from the same clade. Anatomical features are reported in the taxonomic descriptions at the end of the paper; the terminology used is the same as in Köhler (2011b).

\section{Delimitation of species}

Our operational criterion of species delimitation is to determine phenotypically and genotypically distinct clusters (Sites and Marshall, 2004). To this end we employed step-wise evaluation of the mitochondrial and morphological variation ('reciprocal corroboration') to recognize distinct species by using four criteria: (1) distinct species form clades, (2) these clades are well differentiated from other such clades, (3) the morphology of species differs in at least one feature that is unlikely to be polymorphic or under environmental control, (4) no intermediate morphs exist. This procedure is considered a conservative approach in species delimitation. As it requires consistent differentiation in morphological and mitochondrial markers, it would not necessarily recognize morphologically cryptic species or phylogenetically young species sharing ancestral genetic polymorphisms.
For clarity, the following molecular and anatomical comparisons are presented with reference to the newly introduced taxon names. However, the underlying taxon delimitations resulted from the combined assessment of the molecular and anatomical differentiation and were not foregone conclusions preceding these analyses.

\section{Abbreviations}

$16 \mathrm{~S}=16 \mathrm{~S}$ rRNA gene; $\mathrm{ag}=$ albumen gland $;$ at = atrium; $\mathrm{bc}=$ bursa copulatrix; $\mathrm{BI}=$ Bayesian Inference; $\mathrm{COI}=$ cytochrome c oxidase subunit 1 gene; $\mathrm{D}=$ shell diameter; dry = number of dry shell(s); ef = epiphallic flagellum; ep = epiphallus; epp = epiphallic longitudinal pilasters; fo = free oviduct; $\mathrm{H}=$ shell height; $\mathrm{lp}=$ longitudinal pilasters; $\mathrm{ML}=$ Maximum Likelihood; NR, nature reserve; $\mathrm{p}=$ penis; $\mathrm{pd}=$ penial pad-like thickening (penial stimulator); $\mathrm{rm}=$ retractor muscle; $\mathrm{tf}=$ transverse folds; $\mathrm{tl}=$ transverse lamellae; so = spermoviduct; va = vagina; vd = vas deferens; $\mathrm{W}=$ number of whorls of shell; $\mathrm{WA}=$ Western Australia; WAM = Western Australian Museum, Perth; wet $=$ number of ethanol-preserved specimens.

\section{Results}

\section{Molecular analyses}

Analyses of mitochondrial sequences were employed to estimate amounts of genetic variation within and between species, to infer their phylogenetic relationships and to test the monophyly of taxa as delimited by means of their morphology.

We successfully amplified COI and 16S sequences from 145 camaenid specimens as well as additional $16 \mathrm{~S}$ sequences from seven specimens (COI missing). The sequences analysed herein represented 25 camaenid genera (Table S1). The final concatenated data set of aligned sequences of COI and $16 \mathrm{~S}$ had a total length of 1,521 bp (COI: 655 bp, 16S: 866 bp). The missing sequence fragments were coded as unknown.

Xia's et al. (2003) test indicated no or little saturation in both mitochondrial fragments (Iss < Iss.c with $\mathrm{p}<0.01$ ). Sequences of Mesodontrachia fitzroyana Solem, 1985 from the Victoria River District (NT) were used as outgroup to root the trees. This outgroup was selected based on a more comprehensive pilot study containing all north-western Australian Camaenidae (Criscione and Köhler, unpubl. data).

The hierarchical likelihood tests revealed the Tamura-3-parameter model (Tamura, 1992) with gamma 
distribution and proportions of invariable sites $(\mathrm{T} 92+\Gamma+\mathrm{I})$ as the best-fit model of sequence evolution for $16 \mathrm{~S}$, and the HKY model (Hasegawa et al., 1985) with gamma distribution and proportions of invariable sites $(\mathrm{HKY}+\Gamma+\mathrm{I})$ for COI. These evolutionary models were applied in in the partitioned BI analyses. Generations sampled before the chain reached stationary were discarded as burn-in. Stationarity was reached after 6,500,000 generations and 3500 trees were discarded as burn-in.

The BI and ML analyses produced trees with similar topologies that differed in some details (Figs 2-3). For clarity, the terminal clades in Figs 1-2 have been labelled with the names of taxa recognized or described below based on comparative analyses of morphological and molecular data.
Both phylogenies confirmed the monophyly of Kimberleytrachia as presently delimited and both analyses consistently revealed several well supported (in terms of nodal support) and well differentiated (in terms of basal branch lengths) terminal clusters (Figs 2-3). The Bayesian consensus phylogram and the best Maximum Likelihood tree had nearly identical topologies differing mainly in that nodes receiving low ML bootstrap support were unresolved in the BI consensus phylogram (Figs 2-3). Following combined examination of morphological characters (see below), ten of these clades were recognised as already described species. These are all presently recognised species of Kimberleytrachia, excluding two, Kimberleytrachia deflecta (Solem, 1979) and K. hirsuta Köhler, 2011, for which material

Table 1. Intra- and interspecific genetic differentiation among Kimberleytrachia species by means of p-distances. Intraspecific distances shaded. Rows on top: COI, rows below: 16S. Inset: minimum, maximum and average intra- and interspecific p-distances within Kimberleytrachia. Species codes: ach, K. achernaria; aeq, K. aequum; alp, K. alphacentauri; amp, K. amplirhagadoides; can, K. canopi; cha, K. chartacea; cra, K. crawfordi; cru, K. crucis; jac, K. jacksonensis, leo, K. leopardus; nel, K. nelsonensis, ser, K. serrata, set, K. setosa; sil, K. silvaepluvialis; som, K. somniator; umb, K. umbonis. New species marked by an asterisk.

\begin{tabular}{|c|c|c|c|c|c|c|c|c|c|c|c|c|c|c|c|c|}
\hline & ach & aeq & alp & $\mathrm{amp}$ & cha & $\mathrm{cru}$ & som & $\mathrm{jac}^{*}$ & $\mathrm{nel}^{*}$ & cra & ser* & set* & leo* & umb & can & $\operatorname{sil}^{*}$ \\
\hline \multirow[t]{2}{*}{ ach } & - & & & & & & & & & & & & $\min$ & & nax & mean \\
\hline & 0.037 & & & & & & & & & & $\overline{\mathrm{COI}}$ & within & 0.000 & & .059 & 0.026 \\
\hline \multirow[t]{2}{*}{ aeq } & 0.135 & - & & & & & & & & & & between & n 0.055 & & .161 & 0.119 \\
\hline & 0.100 & - & & & & & & & & & $\overline{16 S}$ & within & 0.001 & & .045 & 0.018 \\
\hline \multirow[t]{2}{*}{ alp } & 0.123 & 0.115 & 0.005 & & & & & & & & & between & n $\quad 0.040$ & & .129 & 0.097 \\
\hline & 0.088 & 0.099 & 0.004 & & & & & & & & & & & & & \\
\hline \multirow[t]{2}{*}{ amp } & 0.130 & 0.147 & 0.137 & - & & & & & & & & & & & & \\
\hline & 0.099 & 0.125 & 0.109 & 0.003 & & & & & & & & & & & & \\
\hline \multirow[t]{2}{*}{ cha } & 0.122 & 0.127 & 0.105 & 0.126 & 0.016 & & & & & & & & & & & \\
\hline & 0.071 & 0.095 & 0.096 & 0.087 & 0.007 & & & & & & & & & & & \\
\hline \multirow[t]{2}{*}{ cru } & 0.106 & 0.130 & 0.105 & 0.117 & 0.121 & - & & & & & & & & & & \\
\hline & 0.087 & 0.115 & 0.103 & 0.087 & 0.089 & - & & & & & & & & & & \\
\hline \multirow[t]{2}{*}{ som } & - & - & - & - & - & - & - & & & & & & & & & \\
\hline & 0.079 & 0.107 & 0.087 & 0.097 & 0.074 & 0.093 & - & & & & & & & & & \\
\hline \multirow[t]{2}{*}{ jac* } & 0.105 & 0.127 & 0.086 & 0.105 & 0.069 & 0.102 & - & 0.000 & & & & & & & & \\
\hline & 0.085 & 0.106 & 0.097 & 0.089 & 0.049 & 0.100 & 0.083 & 0.008 & & & & & & & & \\
\hline \multirow[t]{2}{*}{ nel* } & - & - & - & - & - & - & - & - & - & & & & & & & \\
\hline & 0.098 & 0.040 & 0.110 & 0.129 & 0.093 & 0.122 & 0.109 & 0.101 & - & & & & & & & \\
\hline \multirow[t]{2}{*}{ cra } & 0.138 & 0.143 & 0.116 & 0.148 & 0.107 & 0.118 & - & 0.092 & - & 0.059 & & & & & & \\
\hline & 0.091 & 0.110 & 0.110 & 0.111 & 0.089 & 0.093 & 0.102 & 0.103 & 0.108 & 0.041 & & & & & & \\
\hline \multirow{2}{*}{ ser* } & 0.126 & 0.081 & 0.136 & 0.145 & 0.132 & 0.143 & - & 0.122 & - & 0.134 & 0.005 & & & & & \\
\hline & 0.083 & 0.057 & 0.105 & 0.119 & 0.086 & 0.105 & 0.112 & 0.097 & 0.054 & 0.103 & 0.001 & & & & & \\
\hline \multirow[t]{2}{*}{ set* } & 0.126 & 0.139 & 0.126 & 0.140 & 0.120 & 0.115 & - & 0.101 & - & 0.110 & 0.143 & 0.003 & & & & \\
\hline & 0.090 & 0.118 & 0.118 & 0.127 & 0.092 & 0.103 & 0.120 & 0.106 & 0.112 & 0.078 & 0.103 & 0.020 & & & & \\
\hline \multirow[t]{2}{*}{ leo* } & 0.139 & 0.148 & 0.115 & 0.146 & 0.101 & 0.114 & - & 0.096 & - & 0.096 & 0.155 & 0.118 & 0.047 & & & \\
\hline & 0.084 & 0.109 & 0.100 & 0.112 & 0.085 & 0.101 & 0.089 & 0.091 & 0.110 & 0.071 & 0.103 & 0.082 & 0.024 & & & \\
\hline \multirow[t]{2}{*}{ umb } & 0.138 & 0.146 & 0.121 & 0.152 & 0.111 & 0.120 & - & 0.100 & - & 0.065 & 0.146 & 0.116 & 0.092 & 0.045 & & \\
\hline & 0.084 & 0.108 & 0.109 & 0.101 & 0.082 & 0.091 & 0.100 & 0.087 & 0.108 & 0.058 & 0.099 & 0.067 & 0.060 & 0.023 & & \\
\hline \multirow[t]{2}{*}{ can } & 0.122 & 0.134 & 0.125 & 0.124 & 0.115 & 0.108 & - & 0.099 & - & 0.104 & 0.134 & 0.116 & 0.121 & 0.106 & 0.051 & \\
\hline & 0.092 & 0.113 & 0.102 & 0.108 & 0.093 & 0.100 & 0.092 & 0.093 & 0.117 & 0.109 & 0.108 & 0.099 & 0.091 & 0.089 & 0.045 & \\
\hline \multirow[t]{2}{*}{ sil* $^{*}$} & 0.127 & 0.128 & 0.099 & 0.126 & 0.102 & 0.119 & - & 0.084 & - & 0.096 & 0.143 & 0.143 & 0.108 & 0.109 & 0.109 & 0.005 \\
\hline & 0.095 & 0.120 & 0.098 & 0.112 & 0.087 & 0.105 & 0.104 & 0.094 & 0.122 & 0.102 & 0.117 & 0.092 & 0.098 & 0.083 & 0.107 & 0.001 \\
\hline
\end{tabular}




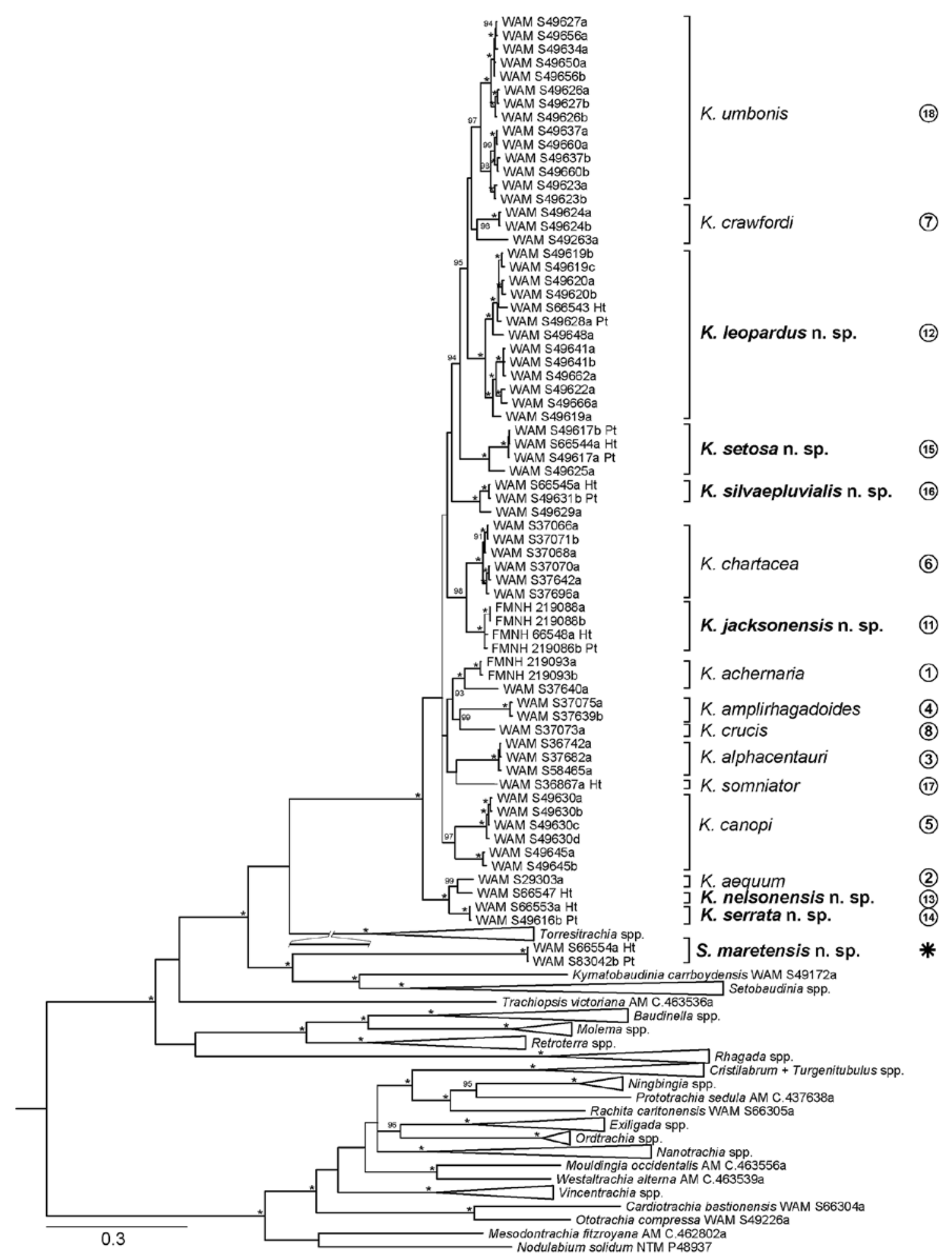

Fig. 2. Bayesian consensus phylogram based on analyses of concatenated COI and 16S sequences. Numbers on branches indicate nodal support (\%) by Bayesian posterior clade probabilities (BPP; only values $\geq 90 \%$ are shown; values of $100 \%$ are represented by asterisks). Thick lines mark branches being consistent with topology of the ML tree. Congeneric sequences of outgroup taxa are collapsed. 


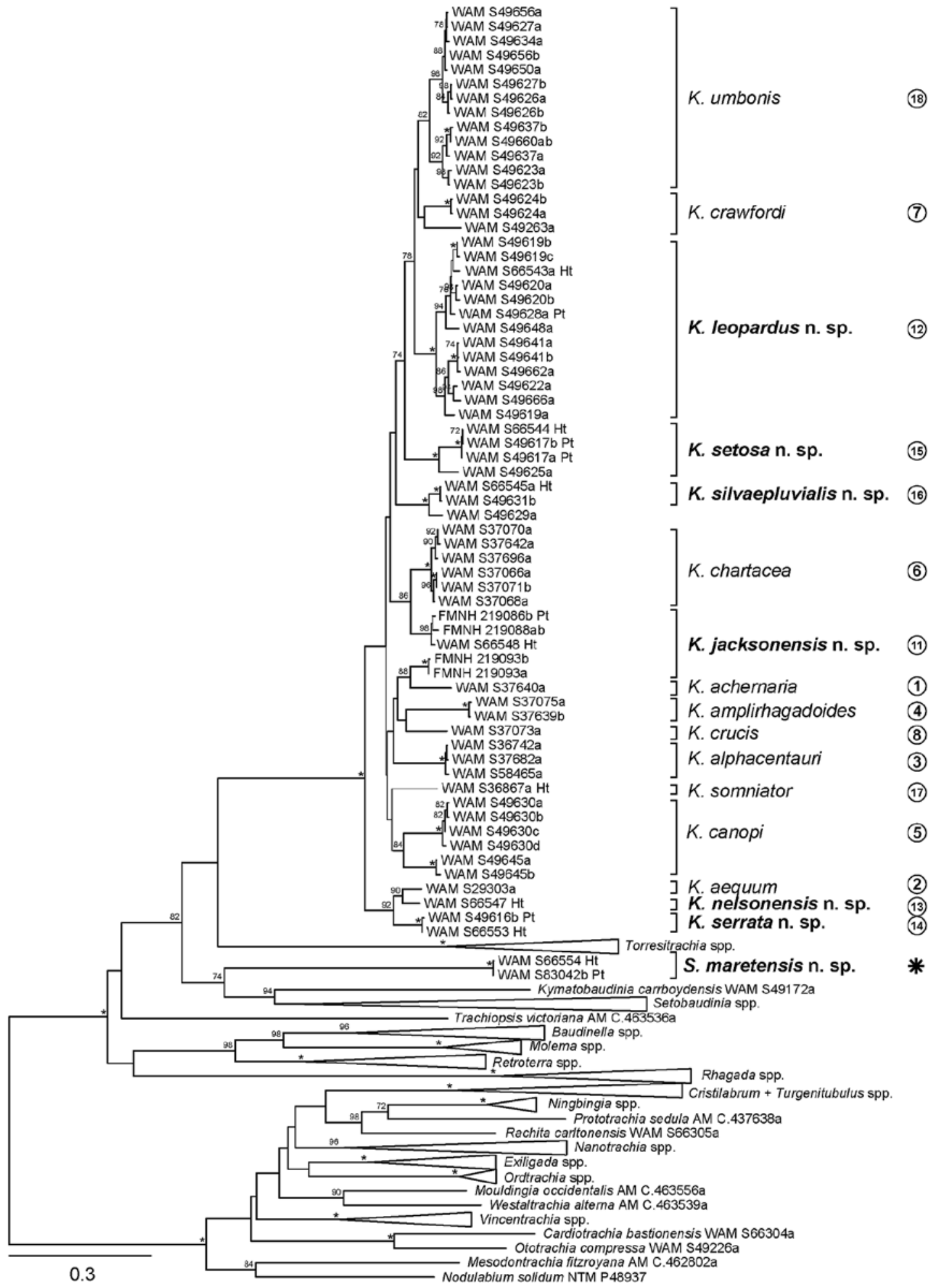

Fig. 3. Maximum Likelihood phylogram based on analyses of concatenated COI and 16S sequences. Numbers on branches indicate nodal support (\%) by ML bootstrap (BTSP; only values $\geq 70 \%$ are shown; values of $100 \%$ are represented by asterisks). Thick lines mark branches being consistent with topology of the BI tree. Congeneric sequences of outgroup taxa are collapsed. 
was not available for molecular analysis. Further seven clades are molecular operational units that represent candidate species whose taxonomic status was assessed by means of comparative anatomy.

The only specimen of lot WAM S49629 had a sister relationship with one of these candidate species $(K$. silvaepluvialis $\mathrm{n}$. sp.). Because of the immature status of this specimen we were unable to examine its genital anatomy and therefore we refrain from a formal identification.

Terminal sequence clusters representing candidate species differed from each other by mean uncorrected pairwise p-distances of 5 to $16 \%$ (average $=12 \%$ ) in COI and 4 to $13 \%$ (average $=10 \%$ ) in $16 \mathrm{~S}$. Within clade pairwise p-distances were below $6 \%($ average $=3 \%)$ in COI and below 5\% (average $=2 \%$ ) in 16S (Table 1$)$. Thus, there has been a slight overlap between withinclade and between-clade p-distances.

Both trees revealed the existence of a second main clade that is phylogenetically distinct from Kimberleytrachia and found in a sister group relationship with a clade containing Setobaudinia Iredale, 1933 and Kymatobaudinia Criscione and Köhler, 2014 (Figs 2-3). This clade represents the below newly described genus 'Succochlea' (see Appendix for the description).

Phylogenetic analyses of the two single-gene datasets (not shown) produced trees consistent with the branching pattern of the phylogenies for the concatenated dataset indicating that the missing sequences had no effect on the topology of these trees.

\section{Comparative morphology}

Morphological examinations and analyses of shell dimensions aimed at documenting and evaluating the amounts of morphological differentiation within and between operational units identified in the mitochondrial phylogeny. In general, shells of Kimberleytrachia can be readily distinguished from those of most other camaenids by a combination of key characters, such as being transparent and brittle, often comparatively large, weakly elevated, having an open umbilicus and being covered by microscopic pustules, often also periostracal projections (setae). In conjunction with the shell, Kimberleytrachia is characterised by a combination of genital features, including the lack of penial sheath and verge and the presence of an epiphallus with flagellum. A peculiarly complex inner penial wall sculpture and frequent presence of a pad-like swelling underneath the opening to epiphallus are distinctive features of this genus. The general configuration of the genital organs is identical in all species of Kimberleytrachia while in particular details of the sculpture of the inner penial wall are species specific.

The shells of species described below differed to varying degrees in shape, sculpture and periostracal microsculpture (Figs 4-8 in Appendix): Kimberleytrachia leopardus n. sp., K. nelsonensis n. sp. and K. serrata $\mathrm{n}$. sp. differ from the other new species by their lower spire (Table 2), while $K$. jacksonensis n. sp., $K$. setosa $\mathrm{n}$. sp. and K. silvaepluvialis $\mathrm{n}$. sp. have more elevated spires (Table 2). Periostracal setae were observed on shells of $K$. jacksonensis n. sp., K. nelsonensis n. sp. and $K$. setosa n. sp., whereas K. leopardus n. $\mathrm{sp}$. and $K$. silvaepluvialis $\mathrm{n}$. sp. exhibited a combination of pustulation and axial sculpture; K. serrata n. sp. exhibited a peculiar teleoconch microsculpture of 'sawteeth-shaped' periostracal projections (Fig. 7C in Appendix), readily distinguishable from that observed in the other species. Generally, the species varied little in their apertural and umbilical morphology as well as shell colour (yellowish-brown).

\begin{tabular}{lccccc}
\hline Species & $\mathrm{N}$ & $\mathrm{H}$ & $\mathrm{D}$ & $\mathrm{H} / \mathrm{D}$ & $\mathrm{W}$ \\
\hline $\begin{array}{l}\text { Kimberleytrachia } \\
\quad \text { jacksonensis }\end{array}$ & 5 & $11.5-13.0$ & $19.4-20.7$ & $0.58-0.63$ & $4.4-4.7$ \\
K. leopardus & & $12.0 \pm 0.6$ & $20.2 \pm 0.5$ & $0.59 \pm 0.02$ & $4.6 \pm 0.2$ \\
& 18 & $9.2-12.0$ & $17.9-23.5$ & $0.47-0.55$ & $4.7-5.5$ \\
K. nelsonensis & & $10.5 \pm 0.8$ & $21.0 \pm 1.5$ & $0.50 \pm 0.02$ & $5.1 \pm 0.2$ \\
& 4 & $9.9-9.9$ & $17.4-19.5$ & $0.48-0.52$ & $4.4-4.6$ \\
K. serrata & & $9.3 \pm 0.4$ & $18.4 \pm 0.9$ & $0.51 \pm 0.02$ & $4.6 \pm 0.1$ \\
& 3 & $6.5-7.0$ & $19.0-22.0$ & $0.30-0.34$ & $4.7-5.0$ \\
K. setosa & & $6.7 \pm 0.3$ & $20.6 \pm 1.5$ & $0.33 \pm 0.02$ & $4.9 \pm 0.2$ \\
& 9 & $9.3-12.4$ & $18.2-23.0$ & $0.48-0.55$ & $4.7-5.1$ \\
Succochlea maretensis & 27 & $12.3-15.4$ & $18.1-20.8$ & $0.74-0.79$ & $4.2-4.7$ \\
& & $13.8 \pm 0.8$ & $19.3 \pm 0.7$ & $0.71 \pm 0.03$ & $4.5 \pm 0.1$ \\
\hline
\end{tabular}

Table 2. Shell dimensions ( $\mathrm{mm}$ ) and whorl counts of taxa recognised herein for $\mathrm{N}$ measured shells. 
The examined species exhibited a rather conserved genital anatomy. Generally, species varied little in the relative lengths of penis, epiphallus, flagellum and free oviduct. The inner penial wall consistently revealed a combination of transverse lamellae and longitudinal pilasters and a pad-like swelling at the distal part of the penial wall. The shape, size and arrangement of sculptural elements of the inner penial wall were speciesspecific (see descriptions in the Appendix).

The genital anatomy of Succochlea n. gen., in particular the sculpture of inner penial wall (Fig. 10B in Appendix), was highly similar with Kimberleytrachia except for its much longer vagina. Unlike Kimberleytrachia, Succochlea n. gen. had no deflected aperture, an extremely reduced apertural lip without basal nodule, no periostracal projections or pustulations. Instead, the protoconch exhibited a distinctive sculpture of radial ridgelets not known from Kimberleytrachia (Figs 4G, 8D-F in Appendix).

\section{Discussion}

\section{Phylogenetic relationships of Kimberleytrachia}

Kimberleytrachia is nested within the Australian camaenid radiation and Torresitrachia is suggested as its sister taxon by our phylogenetic reconstruction (Figs 2-3).

Our phylogeny (Figs 2-3) supports the basal position of a clade including K. aequum Köhler, 2011, K.nelsonensis $\mathrm{n}$. sp. and $K$. serrata $\mathrm{n}$. sp. These species exhibit a rather flat shell $(\mathrm{H} / \mathrm{D}<0.52)$ with periostracal projections on the entire surface (Köhler, 2011b: fig. 218; Figs 4C-D, 6D-F, 7A-C in Appendix). Although most Kimberleytrachia species exhibit a moderately elevated shell $(\mathrm{H} / \mathrm{D}>0.52)$, a flat shell is characteristic for Torresitrachia and all other closely related genera (except Succochlea n. gen. and Rhagada Albers, 1860 [in Martens and Albers, 1860]). Therefore, a flat shell probably represents an ancestral character state in Kimberleytrachia. The penial anatomy of K. aequum and K.nelsonensis $\mathrm{n}$. sp. is assumed to be largely plesiomorphic in possessing all typical features of the genus, such as a well-developed pad-like structure and regular, wellspaced and smooth epiphallic and penial longitudinal pilasters and transverse lamellae (Köhler, 2011b: fig. 220). The inner penial wall sculpture of most other species appears to be characterised by increased complexity (sinuous lamellae as in K. jacksonensis n. sp., presence of pustulation as in K. deflecta, fusion of elements such as in K. somniator Köhler, 2011) or by the loss of features (K. alphacentauri Köhler, 2011).

Kimberleytrachia and Succochlea n. gen. have strikingly similar genital anatomies including a corresponding layout of penis and epiphallus. Despite the remarkable complexity, our phylogeny suggests that these anatomical configurations likely are the result of parallel evolution.

\section{Species delimitation}

In regard to the delimitation of species, the present study confirms conclusions of previous revisions of northwestern Australian camaenid gastropods, such as Exiligada Iredale, 1939 (Criscione et al., 2012), Australocosmica Köhler, 2011 (Köhler, 2011a; Criscione and Köhler, 2013c), Mesodontrachia Solem, 1985 and related camaenids from the Northern Territory (Criscione and Köhler, 2013a), Nanotrachia Köhler and Criscione, 2013, Setobaudinia (Criscione and Köhler, 2013b), Retroterra, Baudinella and Molema Köhler, 2011 (Criscione and Köhler, 2014a) that camaenid species are most reliably identified by a combination of morphological (shell, genital anatomy) and molecular evidence.

By evaluating the combined differentiation in shell, penial morphology and mitochondrial sequences, seventeen morphologically and phylogenetically distinct clusters have been differentiated. These represent ten already known and seven yet undescribed species of Kimberleytrachia (Figs 2-3). One additional species is placed within the new genus Succochlea gen. n. for its morphological and phylogenetic distinctiveness from all other species. Refer below for complete taxonomic descriptions. All these species are well-differentiated by means of their shell and/or genital anatomy.

Two species, K. umbonis (Solem, 1979) and K. leopardus n. sp., revealed considerable intraspecific genetic structuring. Each species includes two distinct mtDNA clades (Figs 2-3). In both cases, the genetic divergence is associated with small geographic distances between populations and morphological homogeneity. It is therefore not deemed to justify formal taxonomic acts.

Generally, the amounts of genetic differentiation between species were comparable with interspecific distances observed in other north-western Australian camaenids, such as $>3 \%$ (COI and 16S) in Exiligada $>4 \%$ (16S, Criscione et al., 2012), Rhagada >4\% (16S) and $>7 \%$ (COI) (Johnson et al., 2012), Setobaudinia $>6 \%$ (COI) and $>9 \%$ (16S) (Criscione and Köhler, 2013b), Amplirhagada Iredale, $1933>8 \%$ (COI) and $>10 \%$ (16S) (Köhler and Johnson, 2012), Nanotrachia $>5 \%$ (COI) and >3\% (16S) (Köhler and Criscione, 2013), 
Baudinella, $>3 \%$ (COI) and $>4 \%$ (16S) Retroterra (Criscione and Köhler, 2014a). In Kimberleytrachia there has been a slight overlap between intra- and interspecific distances as was occasionally also observed in other genera.

Shells are of limited value for the discrimination of Kimberleytrachia species confirming a more general statement by Solem (1981a) on the diagnostic value of shells in camaenids from the Kimberley. The shells of most species are within the same size range of 18 to 25 $\mathrm{mm}$ in diameter, except $K$. alphacentauri and $K$. deflecta having a significantly smaller shell (Köhler, 2011: Table 11). Most shells of Kimberleytrachia species share a subglobose shape but some are discoidal (K. aequum; Köhler, 2011b: fig. 218; K. serrata Fig. 4D) or exhibit a very low spire (K. chartacea Köhler, 2011; Köhler, 2011b: fig. 208, K. leopardus, Fig. 4B and K.nelsonensis, Fig. 4C).

The amount of differentiation in the genital characteristics is frequently not sufficient to satisfactorily delimitate species: The general configuration of the inner penial wall (with proximal lamellae and pad and more than one distal pilaster) is shared by most species, except $K$. alphacentauri having a distinctive sculpture with a single pilaster and lamellae extending distally and almost reaching the gonopore (Köhler, 2011b: fig. 217). There is a species-specific variation in number and relative dimension of sculptural elements, but the divergence is too subtle to be useful as a reliable taxonomic marker. This observation conflicts with findings of several other studies on NW Australian camaenid genera, where the genital anatomy was recognised as the most informative and convenient source of information for identifying species (Solem, 1979, 1981a, 1981b, 1985, 1988, 1997; Köhler, 2010a, 2010b, 2011b, 2011c, Criscione and Köhler, 2013a). However, a similarly conserved genital anatomy has been observed in Torresitrachia (Solem, 1979, 1985; Köhler, 2011b).

Kimberleytrachia species were generally found to be allopatric. Only on Boongaree Island three species were found to occur in sympatry (marked with ' $\mathrm{S}$ ' in Fig. 1): K. aequum, K. alphacentauri and $K$. canopi Köhler, 2011. These species differ markedly in shell size and shape as well as in their genital anatomy - in particular the sculpture of their inner epiphallic and penial walls (Köhler, 2011b). They are not closely related and their sister species are not found on Boongaree Island. Hence, they must have originated from independent colonisers of this island.

For Australian camaenids reinforcement has been hypothesized to explain patterns where morphological divergence in sympatric species has been more pronounced than usual. In Amplirhagada, differences in the genital anatomy between sympatric species are often particularly conspicuous and many of the species with the most highly derived penial anatomy consistently occur in sympatry with at least a second congener (Köhler, 2011b). Correspondingly, the distinct morphology of these three species from Bongaree Island may be indicative of ecological niche partitioning (Chiba, 1999, 2002; Solem, 1981a; Cameron, 1992), enabling them to persist in sympatry.

\section{Patterns of diversification and distribution}

Over many millions of years, the monsoon climate typical of northern Australia has carved the ancient Kimberley sandstones into a deeply dissected landscape with barren plateaus and deep gorges. With its soils being depauperate in nutrients and having a low capacity for storing water, the Kimberley boasts a varied patchwork of vegetation types. Vine thickets, a form of rainforest, thrive only in sheltered places while more exposed areas are covered with grassland, bushland or savannah.

The patchily distributed vine thickets are the preferred habitat for many camaenid groups for their moister and more buffered microclimate. One of the factors believed to contribute to the high diversity of camaenid land snails in the Kimberley is the multiplicity of isolated vine thicket/rainforest patches across the region (Solem, 1991). Created by climate fluctuations throughout the Quaternary and Mid to Late Tertiary (Bowler, 1982), these patches have essentially been acting as habitat refugia whereby gene flow between them has been restricted by intervening unsuitable habitat. Because camaenid land snails are deemed to be rather poor dispersers, the patchy distribution of rainforest species has resulted in allopatric patterns of speciation and endemism throughout the region (Cameron, 1992). This evolutionary scenario has specifically been proposed to explain the multitude of narrowly endemic species of Amplirhagada found throughout the Kimberley (Solem, 1981; Köhler, 2011b).

The basal splits in the topology of mtDNA trees of Kimberleytrachia are shallow (Figs 2-3). This may be indicative of rather simultaneous lineage differentiation throughout the entire range of the genus. The actual evolutionary rates of Kimberleytrachia are unknown. If accelerated evolutionary rates of up to $10 \%$ per million years like those reported from several pulmonates (Thomaz et al., 1996; Chiba, 1999; Thacker and Hadfield, 
2000; Watanabe and Chiba, 2001; Pinceel et al., 2005) were considered, then the average genetic divergence observed between species of Kimberleytrachia could indicate that the initial diversification within Kimberleytrachia may have occurred about 1 Million years ago (Ma). A more moderate evolutionary rate, however, would proportionally place this event further back in time. Consequently, the initial diversification within Kimberleytrachia can cautiously be postulated to have occurred sometime around the Pliocene-Pleistocene boundary, between roughly 1.5 and 3.0 Ma. This period of time was characterized by severe aridification across all major Australian biomes (McLaren and Wallace, 2010) leaving the Kimberley rainforests particularly patchy. Such dynamic landscape changes have generally had a profound effect on the evolution of the Australian biota (e.g. Pepper et al., 2011), including camaenid land snails.

Kimberleytrachia is closely associated with rainforests and vine thickets and species of this genus were exclusively found in vine thickets. Most species occur in the wettest parts of the Kimberley, the Prince Regent Reserve and adjacent areas, which currently receive $1,200 \mathrm{~mm}$ or more of average annual rainfall and which have a current average rainforest cover of more than $5 \%$ of surface area (for maps of rainfall and rainforest cover see Kimber et al., 1991). The coastal regions with a more extensive rainforest cover boast the largest number of species while only three species, $K$. crawfordi (Solem, 1979), K. setosa and K. umbonis, occur further inland and further south in regions that receive at least $800 \mathrm{~mm}$ rainfall and have between 1 and 5\% rainforest cover altogether. For this intimate connection of snails with rainforest habitats, it appears plausible to postulate that the fragmentation of rainforests during the Plio-Pleistocene may have played a significant role in initiating the diversification of distinct lineages.

Available distributional data suggests that species in the wetter parts of the Kimberley mainland have comparatively smaller distributional ranges than the species in the drier parts. This observation seems counter-intuitive because one would expect that denser rainforest cover and wetter climate facilitate dispersal between habitat islands. Accordingly, species distributions should be larger in wetter than in drier parts where rainforest patches are more scarcely distributed. However, in correspondence with the patterns in Kimberleytrachia, it has been demonstrated for other camaenids in north-western Australia that both the species richness per area and the species turnover between adjacent areas are decreasing with increased aridity (Solem and
McKenzie, 1991; Köhler, 2011b; Gibson and Köhler, 2012). Drier areas support fewer species but these species usually have wider distributions. This phenomenon has been explained with the ecological function of rock habitat as litho-refugia. Couper and Hoskin (2008) firstly suggested for lizards that sheltered rock habitats provide environmental conditions similar to rainforests permitting the persistence of rainforest lineages even in areas where rainforests have disappeared. Such lithorefugia have clearly been important for the persistence for several camaenid lineages in drier parts of the Kimberley and even have facilitated their radiation into semi-arid environments, such as on the limestone outcrops of the Victoria Bonaparte bioregion of the East Kimberley (Criscione et al., 2012; Köhler and Criscione, 2013). Accordingly, the survival of $K$. crawfordi, $K$. setos $a$ and $K$. umbonis in inland areas may not exclusively rely on the presence of rainforests. If these species were not as strictly associated with rainforests as their counterparts in wetter areas, then the patchiness of rainforests would be less of an obstacle to their dispersal throughout the landscape; hence their wider distributions. However, the environmental envelope of Kimberleytrachia does apparently not permit their survival under more xeric conditions typical of the northern, southern and interior parts of Kimberley, regions that receive less than $800 \mathrm{~mm}$ of average annual rainfall.

The three species occurring outside of the $>1,200 \mathrm{~mm}$ annual rainfall area (K.crafordi, K. umbonis, K. setosa) are member of the same clade together with a fourth species ( $K$. leopardus). The diversification within this lineage might have been triggered by adaptation to more xeric environments.

Several Kimberleytrachia species are endemic to offshore islands. However, the phylogenetic data suggests that they have differentiated roughly at the same time as the mainland species. During the Pleistocene, the islands inhabited by Kimberleytrachia were repeatedly connected with the mainland due to fluctuating sea levels. Although creating a potential for dispersal between islands and with the mainland, this phenomenon did not influence the patterns of distribution and lineage differentiation on the islands. Similar conclusions were drawn for species of Amplirhagada inhabiting the Kimberley islands (Johnson et al., 2010; Köhler and Johnson, 2012). 


\section{Acknowledgements}

This work has been made possible through financial support from the Australian Government (ABRS grant RF211-10 to FK). Field work in the Prince Regent Reserve was funded by Frog Watch, Western Australian Museum. Special thanks are due to Morgan Laudine (Newcastle) and Michael Shea (AM) for producing illustrations of genitalia and to Sue Lindsay (AM) for conducting the SEM work. We thank three anonymous reviewers for their constructive comments on an earlier manuscript version. Their input has helped to improve the quality of this paper.

\section{References}

Bowler JM. 1982. Aridity in the late Tertiary and Quaternary of Australia. Pp. 35-45 in: Barker WR,Greenslade PJM, eds, Evolution of the flora and fauna of arid Australia. Frewville, SA: Peacock Publ.

Cameron RAD. 1992. Land snail faunas of the Napier and Oscar Ranges, Western Australia; diversity, distribution and speciation. Biological Journal of the Linnean Society 45: 271286.

Chiba S. 1999. Accelerated evolution of land snails Mandarina in the oceanic Bonin Islands: Evidence from mitochondrial DNA sequences. Evolution 53: 460-471.

Chiba S. 2002. Ecological diversity and speciation in land snails of the genus Mandarina from the Bonin Islands. Population Ecology 44: 179-187.

Couper PJ, Hoskin CJ. 2008. Litho-refugia: the importance of rock landscapes for the long-term persistence of Australian rainforest fauna. Australian Zoologist 34: 554-560.

Criscione F, Köhler F. 2013a. Conserved shell disguises diversity in Mesodontrachia land snails from the Australian Monsoon Tropics (Gastropoda: Camaenidae). Zoologica Scripta 42: 389-405.

Criscione F, Köhler F. 2013b. More on snails and islands: molecular systematics and taxonomic revision of Setobaudinia Iredale (Gastropoda : Camaenidae) from the Kimberley, Western Australia, with description of new taxa. Invertebrate Systematics 27: 634-654.

Criscione F, Köhler F. 2013c. Six new species of Australocosmica Köhler, 2011 from the Kimberley islands, Western Australia (Mollusca: Pulmonata: Camaenidae). Zootaxa 3608: 101-115.

Criscione F, Köhler F. 2014a. Molecular phylogeny and taxonomic revision of the genera Baudinella Thiele, 1931, Retroterra Solem, 1985 and Molema Köhler, 2011 endemic to the coastal Kimberley, Western Australia (Gastropoda, Camaenidae). Journal of Zoological Systematics and Evolutionary Research, doi: 10.1111/jzs.12065.

Criscione F, Köhler F. 2014b. Cardiotrachia and Rachita - two new land snail genera from the East Kimberley, Western Australia (Eupulmonata: Camaenidae). Systematics and Biodiversity 12: 55-64.

Criscione F, Law ML, Köhler F. 2012. Land snail diversity in the monsoon tropics of Northern Australia: revision of the genus Exiligada Iredale, 1939 (Mollusca: Pulmonata: Camaenidae), with description of 13 new species. Zoological Journal of the Linnean Society 166: 689-722.
Folmer O, Black M, Hoeh W, Lutz R, Vrijenhoek R. 1994. DNA primers for amplification of mitochondrial cytochrome $\mathrm{c}$ oxidase subunit I from diverse metazoan invertebrates. Molecular Marine Biology and Biotechnology 3: 294-299.

Gibson L, Köhler F. 2012. Determinants of species richness and similarity of species composition of land snail communities on Kimberley islands. Records of the Western Australian Museum Supplement 81: 40-65.

Gibson L, McKenzie NL. 2012. Identification of biodiversity assets on selected Kimberley islands: background and implementation. Records of the Western Australian Museum Supplement 81: 1-14.

Hasegawa M, Kishino H, Yano T. 1987. Man's place in Hominoidea as inferred from molecular clocks of DNA. Journal of Molecular Evolution 26: 132-147.

Iredale T. 1933. Systematic notes on Australian land shells. Records of the Australian Museum 19: 37-59.

Iredale T. 1939. A review of the land Mollusca of Western Australia. Records of the Western Australian Museum and Art Gallery 2: 1-88.

Johnson MS, Hamilton ZR, Teale RJ, Kendrick PG. 2012. Endemic evolutionary radiation of Rhagada land snails (Pulmonata: Camaenidae) in a continental archipelago in northern Western Australia. Biological Journal of the Linnean Society 106: 316-327.

Johnson MS, O’Brien EK, Fitzpatrick JJ. 2010. Deep, hierarchical divergence of mitochondrial DNA in Amplirhagada land snails (Gastropoda: Camaenidae) from the Bonaparte Archipelago, Western Australia. Biological Journal of the Linnean Society 100: 141-153.

Kimber P, Forster J, Behn G. 1991. Mapping Western Australian rainforests - an overview. Pp. 37-40 in: McKenzie NL, Johnston RB, Kendrick PG, eds,Kimberley rainforests of Australia. Canberra: Surrey Beatty \& Sons and Department of Conservation and Land Management Western Australia.

Köhler F. 2010a. Three new species and two new genera of land snails from the Bonaparte Archipelago in the Kimberley, Western Australia (Pulmonata, Camaenidae). Molluscan Research 30: 1-16.

Köhler F. 2010b. Uncovering local endemism in the Kimberley, Western Australia: Description of new species of the genus Amplirhagada Iredale, 1933 (Pulmonata, Camaenidae). Records of the Australian Museum 62: 217-284.

Köhler F. 2011a. Australocosmica, a new genus of land snails from the Kimberley, Western Australia (Eupulmonata, Camaenidae). Malacologia 53: 199-216.

Köhler F. 2011b. The camaenid species of the Kimberley Islands, Western Australia (Stylommatophora: Helicoidea). Malacologia 54: 203-406.

Köhler F. 2011c. Descriptions of new species of the diverse and endemic land snail Amplirhagada Iredale, 1933 from rainforest patches across the Kimberley, Western Australia (Pulmonata, Camaenidae). Records of the Australian Museum 63: 167-202.

Köhler F, Criscione F. 2013. Small snails in a big place: A radiation in the semi-arid rangelands in northern Australia (Eupulmonata, Camaenidae, Nanotrachia n.gen.).Zoological Journal of the Linnean Society 169: 103-123.

Köhler F, Johnson MS. 2012. Species limits in molecular phylogenies: A cautionary tale from Australian land snails (Camaenidae: Amplirhagada). Zoological Journal of the Linnean Society 165: 337-362. 
Köhler F, Shea M. 2012. Youwanjela, a new genus of land snail from the Kimberley, Western Australia (Eupulmonata: Camaenidae). Zoosystematics and Evolution 88: 25-31.

Köhler F, Kessner V, Whisson C. 2012. New records of nonmarine, non-camaenid gastropods (Mollusca: Gastropoda) from islands off the Kimberley coast, Western Australia. Records of the Western Australian Museum Supplement 81: 21-39.

Martens Ev, Albers JC. 1860. Die Heliceen nach natuerlicher Verwandtschaft. 2. Ausgabe Leipzig: Engelmann.

McKenzie NL. 1991. An ecological survey of tropical rainforests in Western Australia: background and methods. Pp. 1-26 in: McKenzie NL, Johnston RB, Kendrick PG, eds, Kimberley rainforests of Australia. Canberra: Surrey Beatty and Sons and Department of Conservation and Land Management Western Australia.

McLaren S, Wallace MW. 2010. Plio-Pleistocene climate change and the onset of aridity in southeastern Australia. Global and Planetary Change 71: 55-72.

Nylander JAA. 2002. MrModeltest v2.0b. Department of Systematic Zoology, Uppsala University, Uppsala.

Pepper M, Ho SYW, Fujita MK, Scott Keogh J. 2011. The genetic legacy of aridification: Climate cycling fostered lizard diversification in Australian montane refugia and left lowlying deserts genetically depauperate. Molecular Phylogenetics and Evolution 61: 750-759.

Pilsbry HA. 1895. Manual of Conchology, structural and systematic, with illustrations of the species. Second series: Pulmonata. Helicidae Volume VII. Conchological Section, Academy of Natural Sciences, Philadelphia.

Pinceel J, Jordaens K, Backeljau T. 2005. Extreme mtDNA divergences in a terrestrial slug (Gastropoda, Pulmonata, Arionidae): accelerated evolution, allopatric divergence and secondary contact. Journal of Evolutionary Biology 18: 1264-1280.

Ronquist F, Huelsenbeck JP. 2003. MRBAYES 3: Bayesian phylogenetic inference under mixed models. Bioinformatics 19: $1572-1574$.

Silvestro D, Michalak I. 2010. A userfriendly graphical front-end for phylogenetic analyses using RAxML (Stamatakis, 2006). Organisms Diversity and Evolution 12: 335-337.

Sites JW, Marshall JC. 2004. Operational criteria for delimiting species. Annual Review of Ecology Evolution and Systematics 35: 199-227.

Solem A. 1979. Camaenid land snails from Western and central Australia (Mollusca: Pulmonata: Camaenidae). I. Taxa with trans-Australian distribution. Records of the Western Australian Museum Suppl. 10: 5-142.

Solem A. 1981a. Camaenid land snails from Western and central Australia (Mollusca: Pulmonata: Camaenidae). II. Taxa from the Kimberley, Amplirhagada Iredale 1933. Records of the Western Australian Museum Suppl. 11: 147-320.

Solem A. 1981b. Camaenid land snails from Western and central Australia (Mollusca: Pulmonata: Camaenidae). III. Taxa from the Ningbing Ranges and nearby areas. Records of the Western Australian Museum Suppl. 11: 321-425.

Solem A. 1984. Camaenid land snails from Western and central Australia (Mollusca: Pulmonata: Camaenidae). IV. Taxa from the Kimberley, Westraltrachia Iredale, 1933 and related genera. Records of the Western Australian Museum Suppl. 17: 427-705.
Solem A. 1985. Camaenid land snails from Western and central Australia (Mollusca: Pulmonata: Camaenidae). V. Remaining Kimberley genera and addenda to the Kimberley. Records of the Western Australian Museum Suppl. 20: 707-981.

Solem A. 1988. New camaenid land snails from the northeast Kimberley, Western Australia. Journal of the Malacological Society of Australia 9: 27-58.

Solem A. 1991. Land snails of Kimberley rainforest patches and biogeography of all Kimberley land snails. Pp. 145-246 in: McKenzie NL, Johnston RB, Kendrick PG, eds,Kimberley rainforests of Australia. Canberra: Surrey Beatty \& Sons and Department of Conservation and Land Management Western Australia.

Solem A. 1997. Camaenid land snails from Western and central Australia (Mollusca: Pulmonata: Camaenidae). VII. Taxa from Dampierland trough the Nullabor. Records of the Western Australian Museum Suppl. 50: 1461-1906.

Solem A, McKenzie NL. 1991. The composition of land snail assemblages in Kimberley rainforests. Pp. 247-263 in: McKenzie NL, Johnston RB, Kendrick PG, eds, Kimberley Rainforests of Australia. Canberra: Surrey Beatty \& Sons and Department of Conservation and Land Management Western Australia.

Sutcharit C, Asami T, Panha S. 2007. Evolution of whole-body enantiomorphy in the tree snail genus Amphidromus. Journal of Evolutionary Biology 20: 661-672.

Tamura K. 1992. Estimation of the number of nucleotide substitutions when there are strong transition-transversion and G+C-content biases. Molecular Biology and Evolution 9: 678-687.

Tamura K, Peterson D, Peterson N, Stecher G, Nei M, Kumar S. 2011. MEGA5: Molecular Evolutionary Genetics Analysis using Maximum Likelihood, Evolutionary Distance, and Maximum Parsimony Methods. Molecular Biology and Evolution 28: 2731-2739.

Thacker RW, Hadfield MG. 2000. Mitochondrial phylogeny of extant Hawaiian tree snails (Achatinellidae). Molecular Phylogenetics and Evolution 16: 263-270.

Thiele J. 1931. Teil 2. Gastropoda: Opisthobranchia und Pulmonata. Pp. 377-778 in: Handbuch der Systematischen Weichtierkunde. Jena: Gustav Fischer Verlag.

Thomaz D, Guiller A, Clarke B. 1996. Extreme divergence of mitochondrial DNA within species of pulmonate land snails. Proceedings of the Royal Society of London B Biological Sciences 263: 363-368.

Watanabe Y, Chiba S. 2001. High within-population mitochondrial DNA variation due to microvicariance and population mixing in the land snail Euhadra quaesita (Pulmonata: Bradybaenidae). Molecular Ecology 10: 2635-2645.

Xia X, Xie Z, Salemi M, Chen L, Wang Y. 2003. An index of substitution saturation and its application. Molecular Phylogenetics and Evolution 26: 1-7.

Received: 11 April 2014

Revised and accepted: 11 July 2014

Published online: 3 October 2014

Editor: J.W. Arntzen 


\section{On-line Supplementary Information (SI)}

S1. Museum registration numbers, voucher status and GenBank accession numbers of samples included in the molecular phylogenetic analyses. 


\section{Appendix}

\section{Taxonomic account and descriptions}

Family Camaenidae Pilsbry, 1895

Genus Kimberleytrachia Köhler, 2011

Torresitrachia - Solem, 1979: 45-92 (partim); 1985:

922-933 (partim); 1991: 178-185

(partim), Solem and McKenzie, 1991: 247-263 (partim).

Kimberleytrachia - Köhler, 2011b: 377-400.

Type species. Kimberleytrachia somniator Köhler, 2011.
Diagnosis. Shell. Medium sized ( $\mathrm{D}=12-24 \mathrm{~mm}$; Table 2), thin or mostly very delicate, discoidal to broadly conical with flat to moderately elevated spire; umbilicus narrowly open, may be partly concealed; protoconch with crowded pustules arranged in radial pattern; teleoconch with or without well-developed thin radial ribs (faint radial growth lines may be present), with welldeveloped microsculpture of periostracal setae or projections (particularly visible in juvenile shells); whorls
A

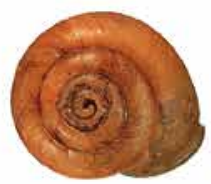

B

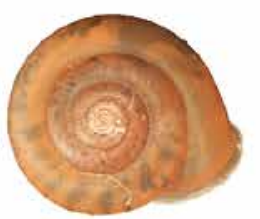

C

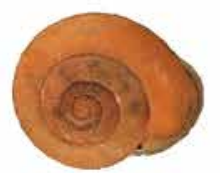

D

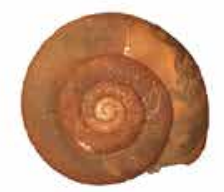

$\mathrm{E}$

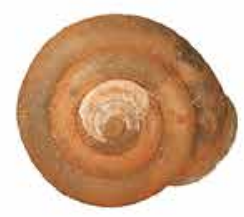

$\mathrm{F}$
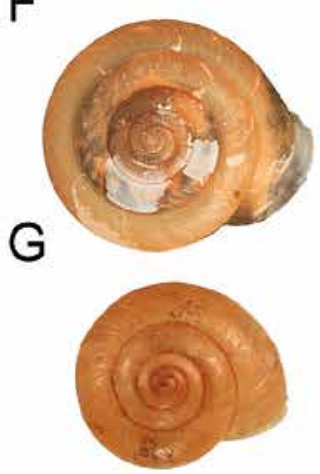
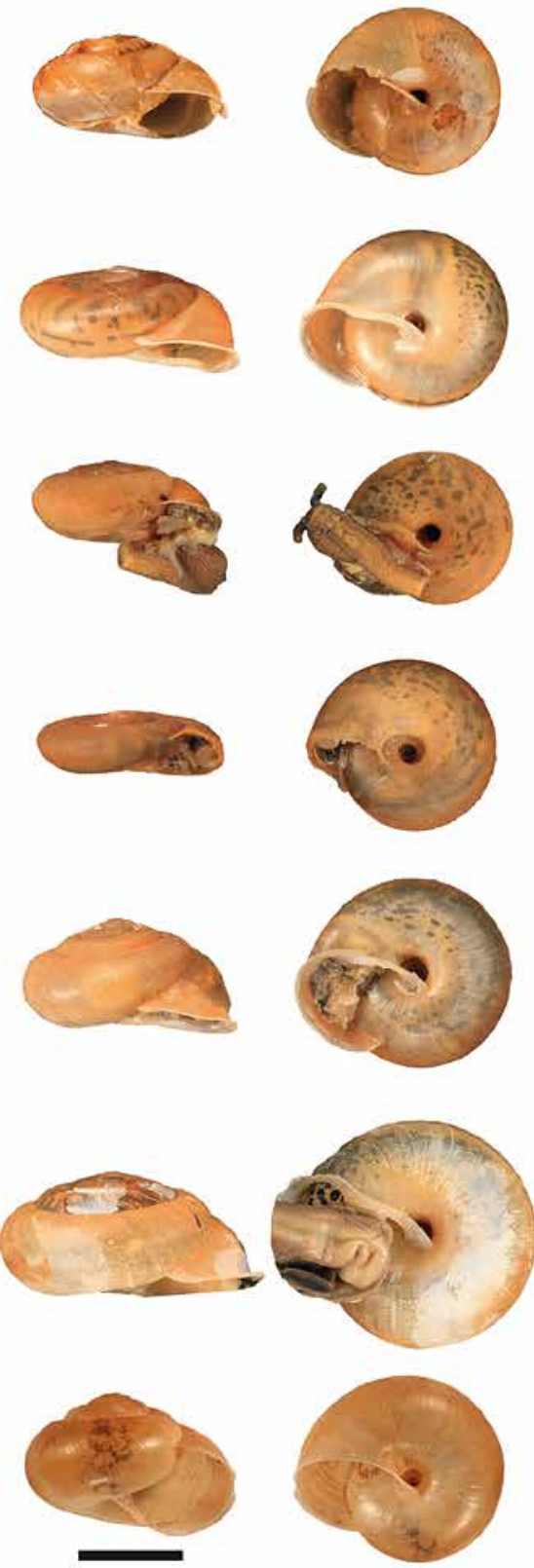

Fig. 4. Shells. (A) K. jacksonensis n. sp. holotype WAM S66548 (B) K. leopardus n. sp. paratype WAM S66543; (C) $K$. nelsonensis $\mathrm{n}$. sp. holotype WAM S66547; (D) $K$. serrata n. sp. paratype WAM S49616; (E) K. setosa n. sp. paratype WAM S49617; (F) K. silvaepluvialis n. sp. holotype WAM S66545; (G) Succochlea maretensis $\mathrm{n}$. gen. $\mathrm{n}$. sp. paratype WAM S83041. Scale bars $=1 \mathrm{~cm}$. Note that mantle pattern of preserved animal is partly visible through transparent shells and that foot tissue protrudes from some shells. 

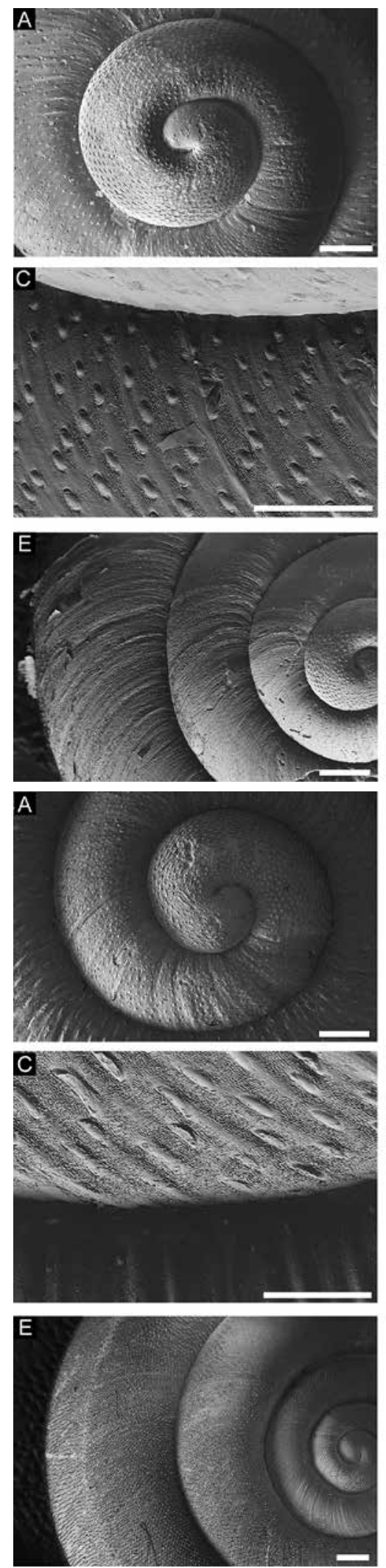
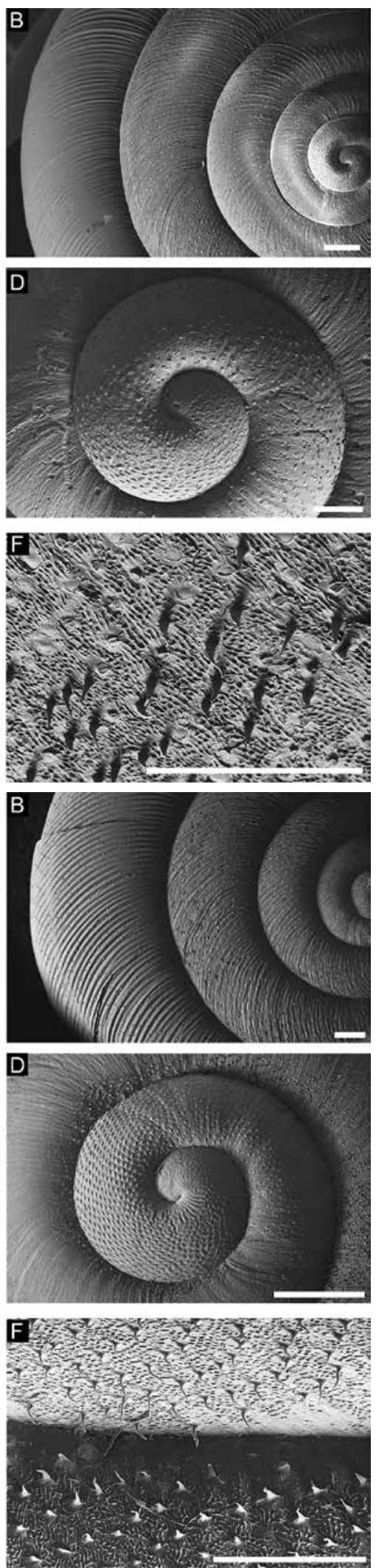

Fig. 5. SEM micrographs showing microsculpture of protoconch and teleoconch. (A-C) $K$. crawfordi Solem, 1979 WAM S49624; (D-F) $K$.jacksonensis n. sp. paratype WAM S66549. Scale bars: $A, C, D, F=500 \mu \mathrm{m} ; B, E=1 \mathrm{~mm}$.

Fig. 6. SEM micrographs showing microsculpture of protoconch and teleoconch. (A-C) $K$. leopardus n. sp. paratype WAM S49628; (D-F) $K$. nelsonensis holotype WAM S66547. Scale bars: $A, C, D, F=500 \mu \mathrm{m} ; B, E=1 \mathrm{~mm}$. 

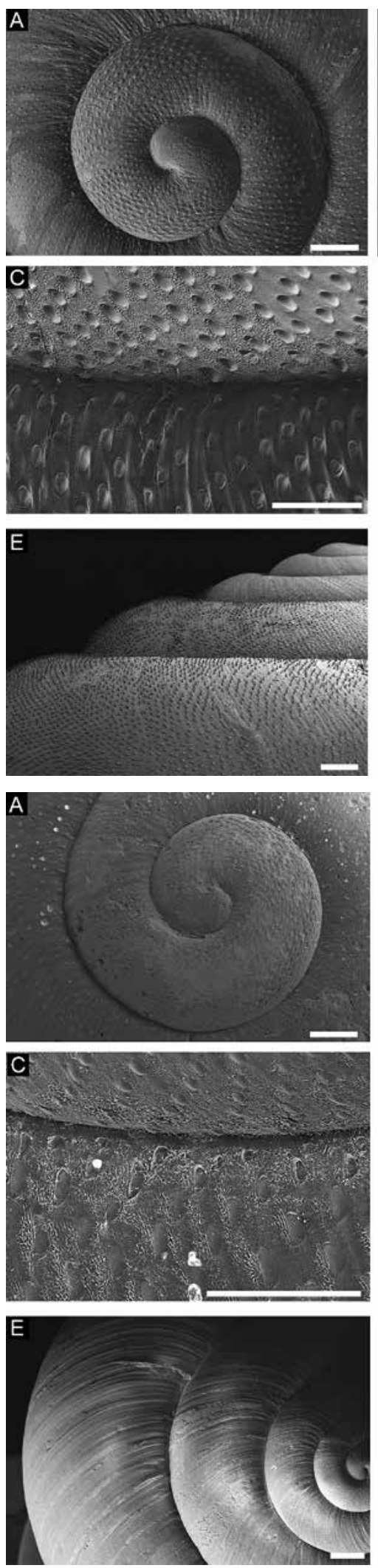
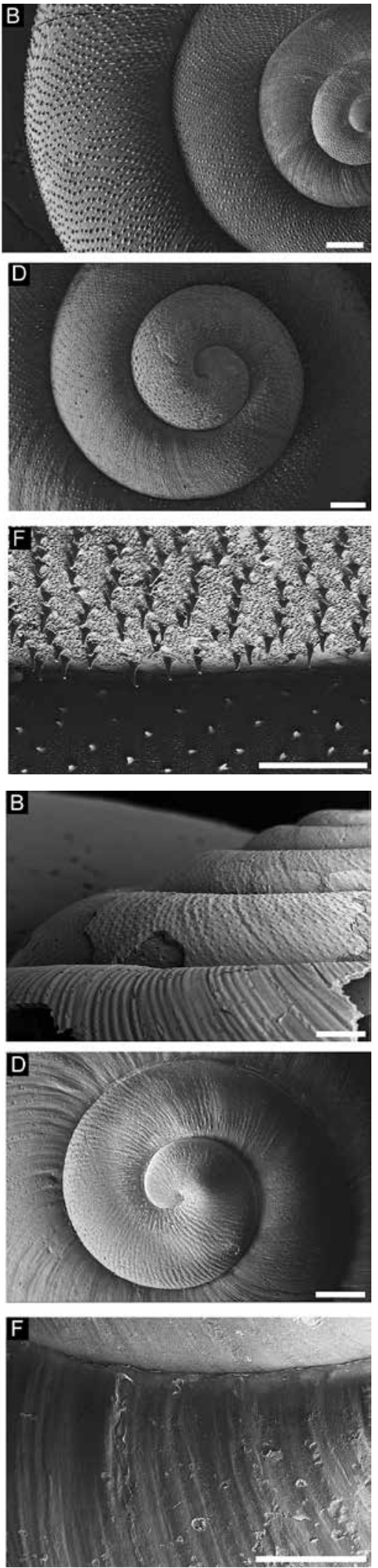

Fig. 7. SEM micrographs showing microsculpture of protoconch and teleoconch. (A-C) $K$. setosa $\mathrm{n}$. sp. paratype WAM S49617; (D-F) $K$. serrata $\mathrm{n}$. sp. paratype WAM S49616. Scale bars: $A, C, D, F=500 \mu \mathrm{m} ; B, E=1 \mathrm{~mm}$.

Fig. 8. SEM micrographs showing microsculpture of protoconch and teleoconch. (A-C) $K$. silvaepluvialis $\mathrm{n}$. sp. holotype WAM S66545; (D-F) Succochlea maretensis n. gen. n. sp. paratype WAM S83041. Scale bars: $A, C, D, F$ $=500 \mu \mathrm{m} ; B, E=1 \mathrm{~mm}$. 

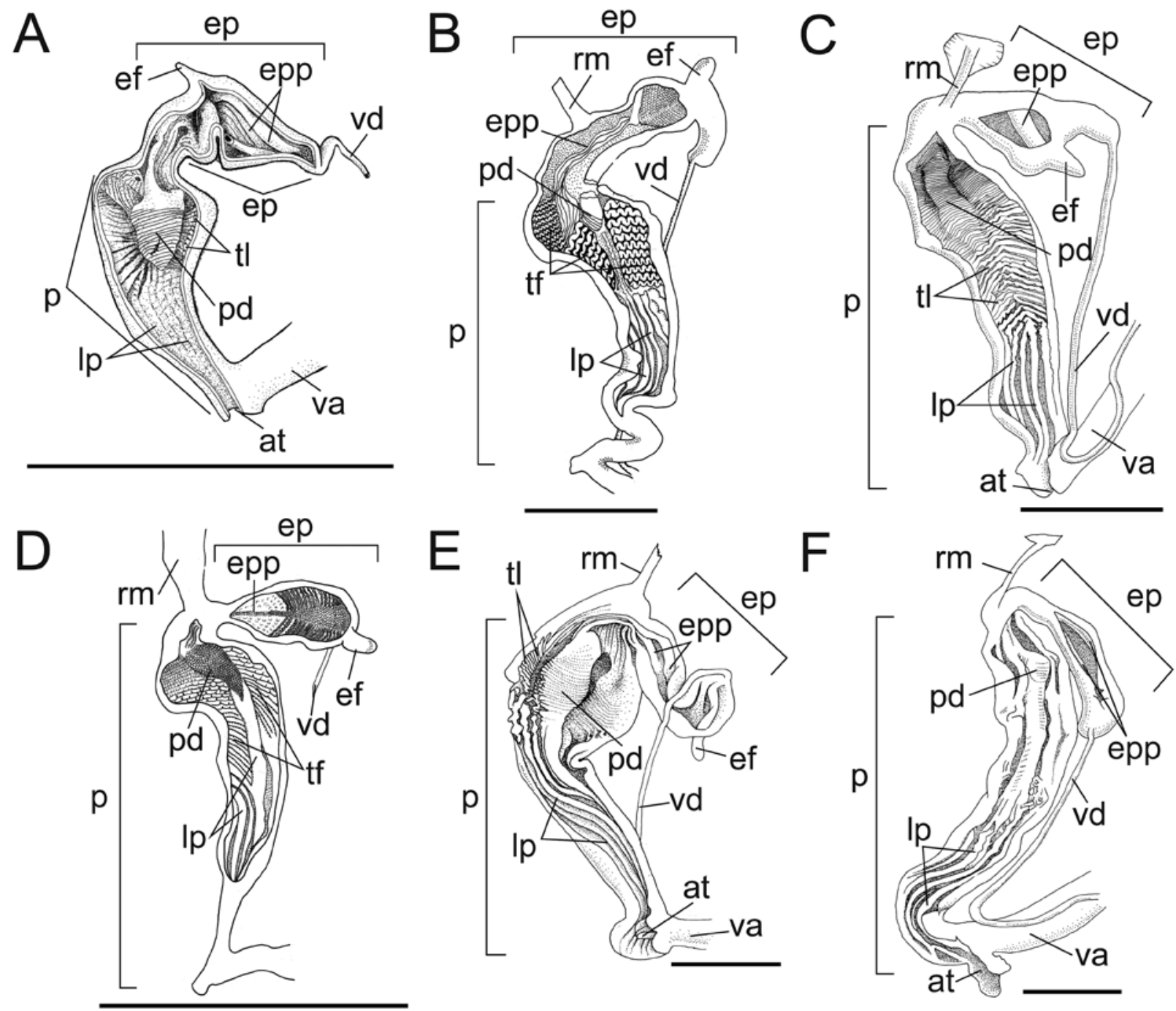

Fig. 9. Penial anatomy. (A) K. crawfordi Solem, 1979 WAM S49624; (B) K. jacksonensis n. sp. holotype WAM S66548; (C) K. leopardus n. sp. holotype WAM S66543; (D) K. nelsonensis n. sp. holotype WAM S66547 (E) K. setosa n. sp. holotype WAM S66544; (F) K. silvaepluvialis $\mathrm{n}$. sp. holotype WAM S66545. Scale bars $=5 \mathrm{~mm}$ (refer to p. 248 for abbreviations).

moderately to slowly increasing, separated by deep suture, periphery well rounded. Shell colour light to yellowish brown, no colour banding. Aperture wide, with relatively thin, weakly to moderately expanded and weakly reflected lip, palatal node absent, basal node weak or absent, parietal wall inconspicuous.

Genital anatomy. Penis without penial sheath, embedded in connective tissue; epiphallus well-developed, with well-developed epiphallic flagellum. Inner penial wall supporting simple to rather complex armature of longitudinal, oblique or transverse pilasters or lamellae, frequently with pad-like swelling underneath opening to epiphallus, pustulation, lateral lamellae or more complex armature may be present. Penial retractor muscle attached at epiphallus between mid-portion to near posterior end. Epiphallus opens to penial lumen through constricting circular vergic ring. Inner epiphallic wall supporting longitudinal pilasters that vary in number and development. Vas deferens rather thin, entering epiphallus laterally near distal end or terminally through slit-like opening or often hose-like extended into lumen of epiphallus. Bursa copulatrix elongate, tubular, reaching anterior end of albumen gland. 
Remarks. The original description of Köhler (2011b) is here emendated to include the presence of radial ribs and fine pustules on the shell of some species. For comparative reasons and in order to complete the documentation of the morphology of all species, we provide illustrations of $K$. crawfordi (Fig. 5A-C, 9A), whose genital anatomy has not been figured before. New records are reported for the following species: K. umbonis (Solem, 1979), K. crawfordi (Solem, 1979), K. canopi Köhler, 2011.

Kimberleytrachia jacksonensis n. sp. (Figs 4A, 5D-F, 9B)

\section{Material examined}

Holotype. Australia, WA, Bonaparte Archipelago, Brunswick Bay, small islet $0.2 \mathrm{~km}$ E of Jackson Island, 15¹0’23” S, 124³9'00” E; coll. 11 Jul 1988 (WAM S66548 wet, dissected).

Paratypes. Same as holotype (FMNH 219086, 5 wet; FMNH 219085, 1 dry; WAM S66549, 2 wet).

Other material. Australia, WA, Bonaparte Archipelago,

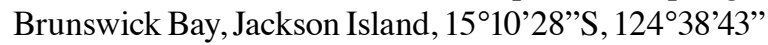
E (11 Jul 1988), 4 wet (FMNH 219088), 4 dry (FMNH 219087), 2 wet (WAM S66551), 3 dry (WAM S66550).

Etymology. For Jackon Island, Latinised adjective of feminine gender.

Description. Shell (Figs 4A, 5D-F). Large to moderate in size (Table 2), delicate, broadly conical with moderately high spire; periphery well rounded; umbilicus 30-60\% concealed; colour yellowish-brown, base of shell lighter, pale yellowish-horn. Protoconch with very fine pustules. Teleoconch with faint growth lines and no radial ribs; entirely covered either with dense, fine, short periostracal projections (setae) extending onto inner umbilical whorls or fine pustules. Aperture moderately wide with moderately expanded, moderately reflected, thin lip; palatal node absent, basal node weakly developed.

Genital anatomy (Fig. 9C). Penis elongate, twice as long as vagina. Distal half of inner penial wall with densely packed transversal folds, broadening proximally; proximal half with longitudinal wide pilasters. Epiphallus almost one third shorter than penis, with thin epiphallic flagellum (ten times shorter than epiphallus); inner epiphallic wall supporting several longitudinal folds along its median portion, terminating into a broad swelling supporting regular pustula- tions. Penial retractor muscle rather short. Free oviduct as long as vagina, two times shorter than bursa copulatrix.

Comparative remarks. Shell size and shape similar to many congeners, differing from $K$. alphacentauri by larger size, from K. aequum, K. chartacea, K. leopardus, $K$. nelsonensis and $K$. serrata by more elevated spire. Shell sculpture differing from K. achernaria, K. cano$p i, K$. silvaepluvialis and K. umbonis by presence of setae on whole teleoconch; not readily differentiated from remaining species based on shell features only. Inner penial wall sculpture similar to $K$. canopi, $K$. deflecta and K. leopardus, differing by sculpture of the inner epiphallic wall.

Distribution. Known only from Jackson Island.

Kimberleytrachia leopardus n. sp. (Figs 4B, 6A-C, 9C)

\section{Material examined}

Holotype. Australia, WA, NW Kimberley, $15 \mathrm{~km} \mathrm{NE}$ of Youwanjela Creek, Prince Regent River NR; 15³1'36” S, 125²1'24” E; coll. V. Kessner, 26 Jan 2010 , gully with vine thicket, sandstone boulders, scree, running stream (WAM S66543, 1 wet, dissected).

Paratypes. Same as holotype (WAM S49628, 12 wet; WAM S49711, 1 dry).

Other, non-type material. Australia, WA, NW Kimberley, Prince Regent River NR: 5 km N of Mt. York, rainforest patch on creek with massive sandstone boulders, under slabs; $15^{\circ} 26^{\prime} 21^{\prime \prime} \mathrm{S}, 125^{\circ} 32$ '23” E (WAM S49648, 1 wet; WAM S49717, 3 dry); about 1.7 km S of Youwanjela Creek, rainforest in gully on upper slopes; 15³6'09" S, 12526’33" E (WAM S49619, 35 wet; WAM S49702, 9 dry); 5.5 km NE of Youwanjela Creek, sandstone terraces with small patches of vine thicket; $15^{\circ} 33^{\prime} 00$ " S, $125^{\circ} 28^{\prime} 51^{\prime \prime}$ E (WAM S49620, 10 wet; WAM S49703, 5 dry); about $72 \mathrm{~km}$ NNE of Bachsten Creek Camp, sandstone terraces, small vine thicket patches; 15¹7'34" S, 12529'50" E (WAM S49622, 5 wet; WAM S49708, 1 dry); 4 km SE of Mt. Brookes, sandstone pavement, on boulders in protected notch in platform; 15¹3'15" S, 125²5'50" E (WAM S49641, 5 wet; WAM S49716, 2 dry); Garimbu Creek, sandstone gorge, vine thicket, under boulders; $15^{\circ} 21^{\prime} 37^{\prime \prime} \mathrm{S}$, 12530'17" E (WAM S49666, 1 wet); 4 km SE of Mt. Brookes, in slot in sandstone pavement, under boulders; 15¹3'12" S, $125^{\circ} 25^{\prime} 55^{\prime \prime}$ E (WAM S49662, 3wet; WAM S49783, 1dry; WAM S49713, 3dry); Prince Regent 
River Nature Reserve, vine thicket in sinkhole, on ceilings of overhangs of massive sandstone boulders, $15^{\circ} 17^{\prime} 32^{\prime \prime} \mathrm{S}, 125^{\circ} 29^{\prime} 43^{\prime \prime}$ E (WAM S49709, 5 dry).

Etymology. For the colour pattern of the mantle roof, resembling leopard fur, visible through transparent shell; characteristic feature of Kimberleytrachia species. Derived from 'leopardus' (Latin = leopard), noun in apposition.

Description. Shell (Figs 4B, 6A-C). Large to moderate in size (Table 2), delicate, broadly conical with low spire; periphery well rounded; umbilicus $60-90 \%$ concealed; colour yellowish-brown, base of shell lighter, pale yellowish-horn. Protoconch with very fine pustules. Teleoconch with marked, very thin radial ribs and well-developed dense, fine pustules, extending on entire shell surface and inner umbilical whorls; periostracal projections not present. Aperture moderately wide with strongly expanded, moderately reflected, thin lip; palatal node absent, basal node well developed.

Genital anatomy (Fig. 9C). Penis elongate, twice as long as vagina. Distal two thirds of inner penial wall with fine and densely packed transversal lamellae, extending onto relatively narrow pad-like swelling, proximal third with longitudinal wide pilasters. Epiphallus almost twice shorter than penis, with thin epiphallic flagellum (five times shorter than epiphallus); inner epiphallic wall supporting one broad longitudinal pilaster along its median portion. Penial retractor muscle rather short. Free oviduct one quarter shorter than vagina, five times shorter than bursa copulatrix.

Comparative remarks. Shell size and shape similar to K. aequum, K. chartacea, K. nelsonensis and K. serrata, differing from those species by presence of radial ribs and absence of periostracal projections. Inner penial wall sculpture similar to $K$. canopi, $K$. crawfordi, $K$. setosa, K.jacksonensis and K. umbonis, differing from the former three species by transverse lamellae covering a larger area and from the latter two by sculpture of the inner epiphallic wall.

Distribution. Northern part of the Regent River catchment within the Prince Regent Nature Reserve (Fig. 1).
Kimberleytrachia nelsonensis n. sp. (Figs 4C, 6D-F, 9D)

\section{Material examined}

Holotype. Australia, WA, Bonaparte Archipelago, Port Nelson, $5 \mathrm{~km}$ N of Mt. Knight, ca. $3 \mathrm{~km}$ E of Careening Bay, 1506'41" S, 12501'53” E; coll. 13 Jul 1988 (WAM S66547).

Paratypes. Same as holotype (FMNH 219150, 2 wet; FMNH 219149, 6 dry; WAM S66546, 4 dry).

Etymology. For Port Nelson, Latinised adjective of feminine gender.

Description. Shell (Figs 4C, 6D-F). Moderate in size (Table 2), delicate, broadly conical with moderately low spire; periphery well rounded; umbilicus less than $30 \%$ concealed; colour yellowish-brown, base of shell lighter, pale yellowish-horn. Protoconch with very fine pustules. Teleoconch with faint growth lines and no radial ribs; entirely covered with dense, fine, short periostracal projections (setae) extending onto inner umbilical whorls. Aperture moderately wide with weakly expanded, weakly reflected, thin lip; palatal node absent, basal node weakly developed.

Genital anatomy (Fig. 9D). Penis elongate, almost twice as long as vagina. Distal portion of inner penial wall with median pad-like swelling supporting fine tubercles and with densely-packed transversal lamellae, becoming less fragmented proximally; proximal portion with wide longitudinal pilaster originating from swelling and narrower pilaster reaching atrium. Epiphallus more than twice shorter than penis, with thin epiphallic flagellum (five times shorter than epiphallus); inner epiphallic wall supporting one longitudinal pilaster along its median portion, proximally thin and distally widening into a broad swelling supporting regular pustulations. Penial retractor muscle wide and short. Free oviduct as long as than vagina, five times shorter than bursa copulatrix.

Comparative remarks. Shell size and shape similar to K. aequum, K. alphacentauri, K. chartacea, K. leopar$d u s$ and $K$. serrata, differing from $K$. achernaria, $K$. canopi, K. silvaepluvialis and K. umbonis by presence of setae on whole teleoconch; not readily differentiated from other congeners based on shell characters only. Inner penial wall sculpture rather distinct from all other species by presence of fragmented lamellae.

Distribution. Known from the type locality only. 
Kimberleytrachia serrata n. sp. (Figs 4D, 7A-C)

\section{Material examined}

Holotype. Australia, WA, NW Kimberley, Prince Regent River Nature Reserve, 14.5 km SSW of Boongaree Is, rainforest patch in a gully, sandstone boulders, scree, 15¹4’00” S, 12506’47” E; coll. V. Kessner, 27 Jan 2010, under rocks (WAM S66553).

Paratypes. Same as holotype (WAM S49616, 5 wet; WAM S49780, 6 dry).

Other, non-type material. Australia, WA, NW Kimberley, upper reaches of Prince Regent River NR, Sandstone outcrops in open woodland, $15^{\circ} 17^{\prime} 03^{\prime \prime} \mathrm{S}, 125^{\circ} 14^{\prime} 25^{\prime \prime} \mathrm{E}$ (WAM S49796, 1dry).

Etymology. For the distinctive shape of periostracal projections on the body whorl, resembling saw teeth. From 'serratus' $($ Latin = serrated, toothed like a saw), adjective in feminine gender.

Description. Shell (Figs 4D, 7A-C). Moderate in size (Table 2), delicate, almost discoidal with low spire; periphery well rounded; umbilicus almost not concealed; colour light brown, base of shell lighter, yellowish-brown. Protoconch with very fine pustules. Teleoconch with faint growth lines and no radial ribs; entirely covered with dense, fine, short periostracal projections, extending onto inner umbilical whorls; projections denticle-shaped on body whorl and with smoother, rounded tips on remaining teleoconch whorls. Aperture narrow with strongly expanded, weakly reflected, thin lip; palatal node absent, basal node moderately developed.

Comparative remarks. Shell size and shape similar to K. aequum, K. alphacentauri, K. chartacea, K. leopar$d u s$ and $K$. nelsonensis, by unique shape of periostracal projections. No adult was collected. Hence, the genital anatomy of this species remains unknown.

Distribution. North of the Prince Regent Reserve, northeast of Prince Frederick Harbour.

\section{Kimberleytrachia setosa n. sp. (Figs 4E, 7D-F, 9E)}

\section{Material examined}

Holotype. Australia, WA, NW Kimberley, S of Bachsten Creek Base Camp, 1559’26” S, 12519'40” E; coll. V. Kessner, M. Maier, 14 Jan 2010, rocky outcrops, small pockets of vine thicket on top of sandstone escarpment, under overhangs (WAM S66544, wet, dissected).
Paratypes. Same as holotype (WAM S49617, 7 wet). Other, non-type material. $4.7 \mathrm{~km} \mathrm{NE}$ of Bachsten Creek Base Camp, sandstone platforms and gully with boul-

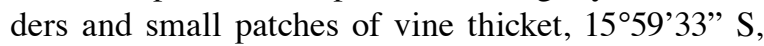
$125^{\circ} 19^{\prime} 44^{\prime \prime}$ E (WAM S49618, 2 wet); Bandicoot Creek, ca $24 \mathrm{~km}$ SE of Bachsten Creek Camp, small pockets of vine thicket on sandstone outcrops, $16^{\circ} 10^{\prime} 31^{\prime}$ S, $125^{\circ} 19^{\prime} 48^{\prime \prime}$ E (WAM S49625, 5 wet); $1.3 \mathrm{~km} \mathrm{~W}$ of Bachsten Creek Base Camp, sandstone outcrops, sandy patches, boulders, $15^{\circ} 59^{\prime} 22^{\prime \prime} \mathrm{S}, 125^{\circ} 19^{\prime} 00^{\prime \prime} \mathrm{E}$ (WAM S49707, 2 dry); Pitta Gorge, rainforest over sandstone scree and soil, $15^{\circ} 52^{\prime} 59^{\prime \prime} \mathrm{S}, 125^{\circ} 35^{\prime} 05^{\prime \prime} \mathrm{E}$ (WAM S49786, 1 dry); $3.5 \mathrm{~km}$ S of Bachsten Creek Base Camp, gully with boulders and small patches of vine thicket, 1601'15”' S, 125¹9'41' E (WAM S49633, 6 dry).

Etymology. In reference to the periostracal projections (setae) on the shell. Derived from 'setosus' (Latin = covered by hairs), adjective of feminine gender.

Description. Shell (Figs 4E, 7D-E). Moderate in size (Table 2), delicate, broadly conical with relatively high spire; periphery well rounded; umbilicus $30-60 \%$ concealed; colour yellowish-brown, base of shell lighter, pale yellowish-horn. Protoconch with very fine pustules. Teleoconch with faint growth lines and no radial ribs; entirely covered with dense, fine, short periostracal projections (setae) extending onto inner umbilical whorls. Aperture wide with strongly expanded, weakly reflected, thin lip; palatal node absent, basal node well developed.

Genital anatomy (Fig. 9E). Penis elongate, almost twice as long as vagina. Distal third of inner penial wall with fine and densely packed transversal lamellae, extending onto relatively narrow and long pad-like swelling, longitudinal wide pilasters at proximal two thirds. Epiphallus twice as long as penis, with thin epiphallic flagellum (ten times shorter than epiphallus); inner epiphallic wall proximal part with two broad longitudinal pilasters, median part proximally essentially smooth, distal part with three longitudinal pilasters (one reflexing into flagellum). Penial retractor muscle long. Free oviduct one quarter shorter than vagina, five times shorter than bursa copulatrix.

Comparative remarks. Shell size and shape very similar to all congeners, differing from K.alphacentauri by larger size and from K. aequum, K. chartacea, K. leopardus and $K$. serrata by more elevated spire. Shell sculpture differing from K. achernaria, K. canopi, $K$. silvaepluvialis and $K$. umbonis by presence of setae on 
whole teleoconch; not readily differentiated from remaining species based on shell features only. Inner penial wall sculpture similar to K. leopardus, K. canopi, K. crawfordi and K. umbonis, differing from the former species by smaller area covered by transverse lamellae and from the latter three by sculpture of the inner epiphallic wall.

Distribution. Together with K. umbonis and K. crawfordi, this species occupies the southernmost parts of the genus' range.

Kimberleytrachia silvaepluvialis n. sp. (Figs 4F, 8A-C, 9F)

\section{Material examined}

Holotype. Australia, WA, NW Kimberley, Prince Regent River NR, $27.4 \mathrm{~km}$ SE of Boongaree Is, 15'18'56” S, $125^{\circ} 21^{\prime} 10^{\prime \prime}$ E; coll. V. Kessner, R. Barrett, M. Maier, 23 Jan 2010, in vine thicket patch in narrow gully, sandstone cliffs and boulders, running stream, under overhangs (WAM S66545, wet, dissected).

Paratypes. Same as holotype (WAM S49631, 2 wet).

Etymology. In reference to the affinity of species of this genus to rainforest ecosystems (vine thickets), derived from 'silva' (Latin = forest) and 'pluvialis' (Latin = of rain), noun and adjective of feminine gender declined to genitive case.
Description. Shell (Figs 4F, 8A-C). Large in size (Ht: $\mathrm{D}=25.3 \mathrm{~mm}, \mathrm{H}=14.3 \mathrm{~mm}, \mathrm{~W}=5.3$ ), delicate, broadly conical with moderately high spire; periphery well rounded; colour yellowish-brown, base of shell lighter, pale yellowish-horn. Protoconch with rather coarse pustules. Teleoconch with marked, very thin radial ribs and well-developed dense, fine pustules, extending on entire shell surface and inner umbilical whorls but restricted to narrow subsutural area on body whorl; periostracal projections not present. Aperture wide with strongly expanded, weakly reflected, thin lip; palatal node absent, basal node well developed.

Genital anatomy (Fig. 9F). Penis elongate, twice as long as vagina. Distal third of inner penial wall with wide pad-like corrugated swelling, tapering into thin corrugated pilasters along wall median third, proximal third with smooth longitudinal pilasters. Epiphallus almost twice as long as penis, with thin epiphallic flagellum (ten times shorter than epiphallus); inner epiphallic wall with abundant, fine, transversal lamellae and several thin, regularly spaced, longitudinal pilasters. Penial retractor relatively short. Free oviduct one third shorter than vagina, five times shorter than bursa copulatrix.

Comparative remarks. Shell size and shape very similar to all congeners, except $K$. alphacentauri, $K$. chartacea and K. leopardus, differing from K. amplirhagadoides Köhler, 2011, K. crawfordi, K. crucis
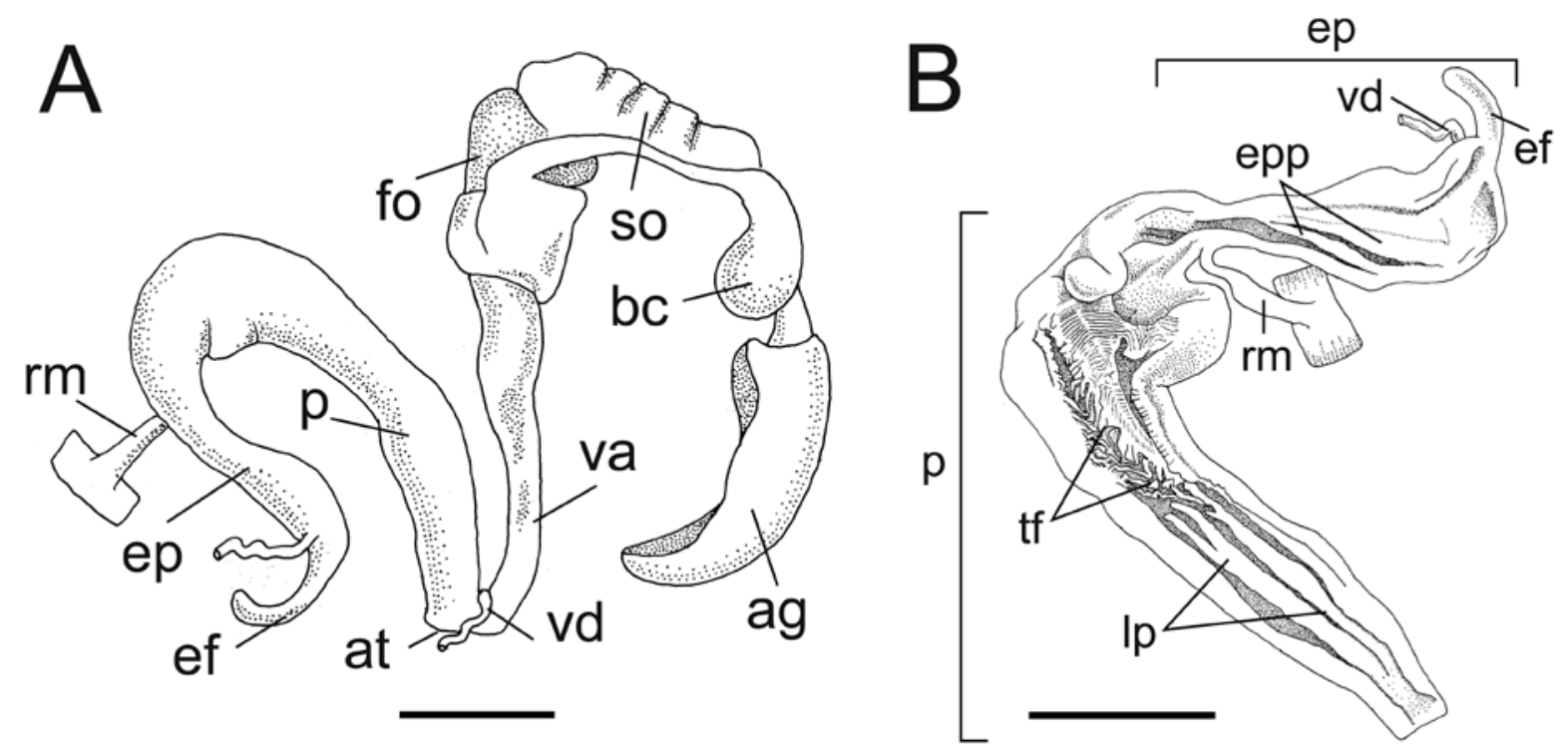

Fig. 10. Genital anatomy of Succochlea maretensis n. gen n. sp. holotype WAM S66554. (A) Whole genitalia; (B) Penis, opened. Scale bars $=5 \mathrm{~mm}$ (refer to p. 248 for abbreviations). 
Köhler, 2011, K. deflecta, K. setosa and K. somniator by absence of setae; not readily differentiated from remaining species based on shell features only. Inner penial wall sculpture very distinctive and similar only to that of $K$. amplirhagadoides, differing from it by sculpture of the inner epiphallic wall. Data available on the morphology of this species come from the holotype, the only adult specimen collected.

Distribution. Known from the type locality only.

\section{Succochlea $\mathrm{n}$. gen.}

Type species. Succochlea maretensis $\mathrm{n} . \mathrm{sp}$.

Etymology. Contraction derived from 'succinum' (Latin $=$ amber) and 'cochlea' (Latin = snail); for 'amber snail' referring to its shell colour; noun of female gender.

Diagnosis. Shell (Figs 4G, 8D-F). Moderate, moderately elevated, moderately deep suture. Umbilicus open, wide, partially concealed by outer lip reflection. Protoconch sculpture of axial ridgelets. Teleoconch microsculpture of thin axial ribs. Aperture wide, not deflected from axis of coiling; outer lip thin.

Genital anatomy (Fig. 10A-B). Penis without penial sheath, embedded in connective tissue; epiphallus welldeveloped, with well-developed epiphallic flagellum. Inner penial wall supporting armature of pilasters or lamellae, with pad-like swelling underneath opening to epiphallus. Penial retractor muscle attached at epiphallus between mid-portion to near posterior end. Epiphallus opens to penial lumen through constricting circular vergic ring. Vas deferens rather thin, entering epiphallus laterally near distal end through slit-like opening or often hose-like extended into lumen of epiphallus. Bursa copulatrix elongate, tubular, reaching anterior end of albumen gland.

Comparative remarks. Shell easily distinguished from most of other camaenids genera in the region by combination of thinness, lack of teleoconch macro- and micro- sculpture. Shell also very similar to Kimberleytrachia, differing from the latter by having a distinctive protoconch microsculpture of radial ribs, less pronouncedly descending body whorl, reduced apertural lip, lacking basal nodule, periostracal projections and pustulation. Genitalia differ from Kimberleytrachia by vagina longer than penis.

Succochlea maretensis n. sp. (Figs 4G, 8D-E, 10A-B)

\section{Material examined}

Holotype. Australia, WA, Bonaparte Archipelago, North Maret Island, 14²3'56” S, 12458'23” E; coll. V. Kessner, A. Longbottom, 15 Jul 1988 (WAM S66554, wet, dissected).

Paratypes. Same as holotype (WAM S83042, 8 wet; WAM S83041, 23 dry; FMNH 219185, 7 wet; FMNH 219184, 22 dry).

Other, non-type material. Australia, WA, Bonaparte Archipelago, SW corner of Berthier Island, 14'30'45" S, 124 $58^{\prime} 50^{\prime \prime}$ E (WAM S83040, 2 dry, 1 wet); South Maret Island, $14^{\circ} 26^{\prime} 27^{\prime \prime}$ S, 1245' $38^{\prime \prime}$ E (WAM S83043, 4 dry; FMNH 219187, 4 dry); unnamed island between Maret and Berthier Islands, $14^{\circ} 28^{\prime} 53^{\prime \prime} \mathrm{S}$, $125^{\circ} 00$ '13" E (WAM S83045, 5 wet; WAM S83044, 6 dry; FMNH 219202, 5 wet; FMNH 219201, 7 dry).

Etymology. For Maret Island, Latinised adjective of feminine gender.

Description. Shell (Figs 4G, 8D-F). Large to moderate in size (Table 2), delicate, broadly conical with high spire; periphery well rounded; umbilicus $30 \%$ concealed; colour golden yellowish-brown, base of shell lighter, pale yellowish-horn. Protoconch with axial ridgelets. Teleoconch with faint, very thin radial ribs and no pustulations; periostracal projections not present. Aperture moderately wide with weakly expanded, not reflected, thin lip; palatal and basal nodes absent.

Genital anatomy (Fig. 10). Penis elongate, slightly shorter than vagina. Distal half of inner penial wall with relatively narrow pad-like swelling, covered by fine and densely packed transversal lamellae, proximal half with longitudinal wide pilasters. Epiphallus almost as long as penis, with thin epiphallic flagellum (three times shorter than epiphallus); inner epiphallic wall supporting three broad longitudinal pilasters. Penial retractor muscle rather short. Free oviduct as long as vagina, twice shorter than bursa copulatrix.

Distribution. Known from the Maret and Berthier island group only. 